\title{
1 A Mathematical Model for Reactions during Top-Blowing in the AOD \\ 2 Process: Derivation of the Model
}

3 Ville-Valtteri Visuri, ${ }^{1{ }^{*}}$ Mika Järvinen, ${ }^{2)}$ Aki Kärnä, ${ }^{1)}$ Petri Sulasalmi, ${ }^{1)}$

4 Eetu-Pekka Heikkinen, ${ }^{1)}$ Pentti Kupari ${ }^{3)}$ and Timo Fabritius ${ }^{1)}$

6 1) Process Metallurgy Research Unit, University of Oulu, PO Box 4300, FI-90014 University of Oulu, Finland.

7 2) Department of Mechanical Engineering, Aalto University, PO Box 14440, FI-00076 Aalto, Finland.

8 3) Outokumpu Stainless Oy, FI-95490 Tornio, Finland.

$9 \quad *$ ) Corresponding author. E-mail: ville-valtteri.visuri@oulu.fi

\section{Abstract}

11 In earlier work, a fundamental mathematical model was proposed for side-blowing operation in the 12 argon-oxygen decarburization (AOD) process. The purpose of this work is to present a new model, 13 which focuses on the reactions during top-blowing in the AOD process. The model considers 14 chemical reaction rate phenomena between the gas jet and the steel bath as well as between the gas 15 jet and metal droplets. The rate expressions were formulated according to a law of mass action based 16 method, which accounts for the mass transfer resistances in the liquid metal, gas and slag phases. The 17 generation rate of the metal droplets was related to the blowing number theory. This paper presents 18 the description of the model, while validation and preliminary results are presented in the second part 19 of this work.

21 Keywords: stainless steelmaking, AOD process, top-blowing, mathematical modelling. 
23 The argon-oxygen decarburization (AOD) process is the most common process for the refining of 24 stainless steel. ${ }^{[1]}$ Owing to violent agitation caused by the high blowing rates, the AOD vessel has very good mixing characteristics. ${ }^{[2-5]}$ Nowadays, top-blowing is employed in conjunction with sideblowing in the early part of the decarburization stage in order to maximize oxygen delivery into the melt. ${ }^{[6]}$ As illustrated in Figure 1, two main reaction areas can be identified during combined blowing: 1) inside the gas plume, and 2) on the surface of the bath, including metal droplets. ${ }^{[7,8]}$

\section{Figure 1}

Numerous reaction models have been proposed for the decarburization ${ }^{[8-37]}$ and nitrification ${ }^{[7,38-40]}$ of steel in an AOD vessel. The majority of the models applicable for side-blowing decarburization have been reviewed elsewhere ${ }^{[21,41]}$. Despite the vast number of reaction models available, there are only a few models that explicitly address the reactions during top-blowing in the AOD process. Arguably the most relevant examples found in the literature are those proposed by Watanabe and Tohge ${ }^{[9]}$, Tohge et al. ${ }^{[17]}$, Kikuchi et al. ${ }^{[23,42]}$ and Wei et al. ${ }^{[8,21,22,26,28]}$. Some similarities in the modelling setting can be found in the reaction models proposed for the VOD process ${ }^{[41,43]}$. To summarize, it can be stated that the top-blowing models proposed so far are capable of predicting the decarburization with a reasonable degree of accuracy and have laid the basic foundations for further investigations. However, more research is required along these lines in order to obtain information on the related reaction interfaces and chemical reaction rate phenomena.

In our previous work, ${ }^{[29,30]}$ a fundamental model was proposed and validated for the reactions inside the bath during side-blowing in the AOD process. Consequently, the aim of this work was to extend the original model by developing a mathematical model for reactions during top-blowing. In order to provide more information on the controlling mechanisms and dynamics of decarburization during top-blowing, the model combines the transient solution of multicomponent equilibria with a description of the constraining mass transfer. This paper presents the description of the model, while validation and preliminary results are presented in the second part of this work ${ }^{[44]}$.

\section{Derivation of the model}

53 The model was programmed using $\mathrm{C}++$ and its main assumptions can be summarized as follows: 
bath, or escape through the gas exit.

2. Reactions between gas, metal and slag species take place simultaneously at the surface of the cavity as well as at surface of the metal droplets generated due to top-blowing.

3. Owing to the high temperature, the reaction rates are assumed to be limited by mass transfer onto and from the reaction interfaces and hence the reaction interfaces are able to reach their constrained thermodynamic equilibrium at any given moment.

4. Conservation of mass and heat are solved successively.

The liquid metal phase is assumed to consist of $\mathrm{Fe}$ as the solvent and $\mathrm{Cr}, \mathrm{Mn}, \mathrm{Si}, \mathrm{C}, \mathrm{O}, \mathrm{N}, \mathrm{Ni}, \mathrm{Al}$ and $\mathrm{S}$ as solutes. The gas phase consists of $\mathrm{O}_{2}, \mathrm{CO}, \mathrm{CO}_{2}, \mathrm{~N}_{2}$ and Ar. The slag phase consists of FeO,

$$
\begin{aligned}
& \left\{\mathrm{O}_{2}\right\} \rightleftharpoons 2[\mathrm{O}], \\
& {[\mathrm{C}]+\frac{1}{2}\left\{\mathrm{O}_{2}\right\} \rightleftharpoons\{\mathrm{CO}\},} \\
& {[\mathrm{C}]+\left\{\mathrm{O}_{2}\right\} \rightleftharpoons\left\{\mathrm{CO}_{2}\right\},} \\
& \mathrm{Fe}_{(\mathrm{l})}+\frac{1}{2}\left\{\mathrm{O}_{2}\right\} \rightleftharpoons(\mathrm{FeO}), \\
& 2[\mathrm{Cr}]+\frac{3}{2}\left\{\mathrm{O}_{2}\right\} \rightleftharpoons\left(\mathrm{Cr}_{2} \mathrm{O}_{3}\right), \\
& {[\mathrm{Mn}]+\frac{1}{2}\left\{\mathrm{O}_{2}\right\} \rightleftharpoons(\mathrm{MnO}),} \\
& {[\mathrm{Si}]+\left\{\mathrm{O}_{2}\right\} \rightleftharpoons\left(\mathrm{SiO}_{2}\right) .}
\end{aligned}
$$

69

The rate expressions were formulated as reversible according to a modified Law of Mass Action, a method that has been discussed more comprehensively in our earlier work ${ }^{[45,46]}$. More specifically, the rate expressions are defined so that concentrations are replaced with activities and partial pressures, as illustrated below for the oxidation of dissolved carbon to carbon monoxide:

$$
R^{\prime \prime}=k_{\mathrm{f}}\left(a_{[\mathrm{C}]} p_{\mathrm{O}_{2}}^{1 / 2}-\frac{p_{\mathrm{CO}}}{K}\right)
$$

where $k_{\mathrm{f}}$ is the forward reaction rate coefficient, $a_{[\mathrm{C}]}$ is the activity of dissolved carbon, $p_{\mathrm{O}_{2}}$ is the partial pressure of gaseous oxygen and $K$ is the equilibrium constant. 


\subsection{Conservation of mass}

80 The observed system consists of gas input, gas exit, two reaction interfaces and three bulk volumes,

81 as shown in Figure 2. It should be noted that the reaction interfaces have neither thickness nor mass. 82

\section{Figure 2}

It has been proposed that during simple side-blowing, post-combustion takes place in the off-gas flue, but not in the AOD vessel itself. ${ }^{[47]}$ However, during combined top- and side-blowing a part of the top-blown oxygen may be consumed in the post-combustion of $\mathrm{CO}$ to $\mathrm{CO}_{2}$ before the gas jet impacts the bath surface. ${ }^{[8]}$ In order to simplify the modelling setting, the model proposed in this paper considers post-combustion only at the reaction interfaces. Because the entrainment of cold air from the atmosphere outside the vessel can be neglected under normal operating conditions, ${ }^{[48]}$ the toplance and the tuyères can be taken as the only gas inputs of the system. More specifically, it was assumed that the side-blown gas exits the metal bath through the plume eye and becomes in contact with the top-blown gas. The mass flow of gaseous species through the top lance into the observed system is given by

$$
\dot{m}_{\mathrm{G}, \text { in,lance }}=\dot{V}_{\mathrm{G}, \text { lance }} \rho_{\mathrm{G}, \mathrm{STP}}
$$

96

where $\dot{V}_{\mathrm{G}, \text { lance }}$ is the volumetric gas flow rate through top lance (in $\mathrm{Nm}^{3} / \mathrm{s}$ ) and $\rho_{\mathrm{G}, \mathrm{STP}}$ is the density of the gas mixture under standard temperature and pressure according to the DIN 1343 standard $^{[49]}$ : $273.15 \mathrm{~K}\left(0{ }^{\circ} \mathrm{C}\right)$ and $101325 \mathrm{~Pa}$. The model is coupled with the earlier-proposed model for sideblowing decarburization ${ }^{[29]}$, which calculates the mass flow of gaseous species from the plume eye ( into the observed system. In the case of inert gases, the mass flow rate of gas from the plume eye is equal to the mass flow rate of gas from the tuyères. Preventing the suction of atmospheric gas, the mass flux of gas exiting the system is obtained from

$$
\dot{m}_{\mathrm{G}, \text { out }}=\max (\underbrace{\dot{m}_{\mathrm{G}, \text { in,lance }}+\dot{m}_{\mathrm{G}, \text { in plume }}}_{\text {gas injection }} \underbrace{-\dot{m}_{\mathrm{G}, \mathrm{cav}}-\dot{m}_{\mathrm{G}, \mathrm{md}}}_{\text {gas consumption }}, 0) \text {, }
$$

where $\dot{m}_{\mathrm{G}, \text { in,plume }}$ is the mass flow of gas from the plume eye, $\dot{m}_{\mathrm{G}, \mathrm{cav}}$ is the mass flow of gas from the cavity interface and $\dot{m}_{\mathrm{G}, \mathrm{md}}$ is the mass flow of gas from the metal droplet interface. In order to avoid the mathematical complexity of the Maxwell-Stefan equations and the generalized Fick's law, an effective diffusion model was employed ${ }^{[50]}$. The conservation of species at the two reaction 
110 interfaces is defined by the reaction rates and mass transfer onto and from the reaction surfaces. 111 Employing a first-order upwind scheme for the Stefan flow, the conservation of species $i$ in phase $\psi$ 112 at reaction interface $\omega$ is given by

113

$$
\begin{aligned}
& \underbrace{\beta_{i, \psi, \omega} \rho_{\psi, \omega}\left(y_{i, B}-y_{i, \omega}^{*}\right)}_{\text {mass transport }} \underbrace{+\max \left(m_{\psi, \omega}^{\prime \prime}, 0\right) y_{i, B}-\max \left(-m_{\psi, \omega}^{\prime \prime}, 0\right) y_{i, \omega}^{*}}_{\text {Stefan flow }} \\
& +\underbrace{\sum_{k=1}^{r} R_{k, \omega}^{\prime \prime} \bar{v}_{i, k}}_{\text {chemical reactions }}=0,
\end{aligned}
$$

115 where $\beta$ is the mass transfer coefficient, $\rho$ is the density, $y_{i, B}$ is the mass fraction of species $i$ in the 116 bulk phase (i.e. steel bath, gas jet or top slag), $y_{i, \omega}^{*}$ is the interfacial mass fraction of species $i, m^{\prime \prime}$ is 117 the total mass flux, $R^{\prime \prime}$ is the reaction rate and $\bar{v}$ is the mass-based stoichiometric coefficient. It should 118 be noted that all properties are specific to the reaction interface in question. In order to account for 119 conservation of mass within the metal droplets, the following expression is employed for species in 120 the metal phase at the metal droplet interface:

$$
\begin{aligned}
& \underbrace{\left(\frac{m_{\mathrm{md}}}{A_{\mathrm{md}} \bar{t}_{\mathrm{md}}}-m_{\mathrm{L}, \mathrm{md}}^{\prime \prime}\right) \bar{\eta}_{i, \mathrm{M}, \mathrm{md}}\left(y_{i, \mathrm{bath}}-y_{i, \mathrm{md}}^{*}\right)}_{\text {mass transport }} \\
& \underbrace{+m_{\mathrm{L}, \mathrm{md}}^{\prime \prime} y_{i, \mathrm{bath}}}_{\text {Stefan flow }}+\underbrace{\sum_{k=1}^{r} R_{k, \mathrm{md}}^{\prime \prime} \bar{v}_{i, k}}_{\text {chemical reactions }}=0,
\end{aligned}
$$

where $m_{\mathrm{md}}, A_{\mathrm{md}}$ and $\bar{t}_{\mathrm{md}}$ are the mass, surface area and average residence time of the metal droplets, respectively, and $\bar{\eta}_{i, \mathrm{M}, \mathrm{md}}$ is the average microkinetic efficiency for mass transfer of species $i$ in the metal droplets. The total mass flux of the metal phase is subject to constraint $m_{\mathrm{L}, \mathrm{md}}^{\prime \prime} \leq \frac{m_{\mathrm{md}}}{A_{\mathrm{md}} \bar{t}_{\mathrm{md}}}$. The average microkinetic efficiency was calculated based on the average residence time of the metal

$$
\bar{\eta}_{i, \mathrm{M}, \mathrm{md}}=\frac{y_{i, \mathrm{bath}}-y_{i, \mathrm{md}}}{y_{i, \mathrm{bath}}-y_{i, \mathrm{md}}^{*}}=1-\exp \left(-\beta_{i, \mathrm{~L}, \mathrm{md}} \frac{A_{\mathrm{md}}}{V_{\mathrm{md}}} \bar{t}_{\mathrm{md}}\right),
$$




$$
\bar{v}_{i, k}=v_{i, k} \frac{M_{i}}{M_{K, k}}
$$

133

134 where $v_{i, k}$ is the stoichiometric coefficient of species $i$ in reaction $k, M_{K, k}$ is the molar mass of the 135 key component of reaction $k$ and $M_{i}$ is the molar mass of species $i$. The key components of the 136 137 138

$$
m_{\psi, \omega}^{\prime \prime}=-\sum_{i=1}^{n} \sum_{k=1}^{r} \Gamma_{i, \psi} R_{k, \omega}^{\prime \prime} \bar{v}_{i, k}
$$

139

where $\Gamma_{i, \psi}$ is a binary operator, which is defined as 1 if species $i$ is in phase $\psi$ and 0 otherwise. The total mass flows $\dot{m}_{\psi, \omega}$ are obtained by multiplying the mass flux $m_{\psi, \omega}^{\prime \prime}$ by the corresponding interfacial area $A_{\omega}$. Employing the implicit Euler method for time integration, the conservation of species $i$ in the steel bath, top-blown gas and top slag is defined by Eqs. 16, 17 and 18, respectively.

$$
\begin{aligned}
& -\beta_{i, \mathrm{~L}, \mathrm{cav}} \rho_{\mathrm{L}, \mathrm{cav}} A_{\mathrm{cav}}\left(y_{i, \mathrm{bath}}-y_{i, \mathrm{cav}}^{*}\right)-\max \left(m_{\mathrm{L}, \mathrm{cav}}^{\prime \prime}, 0\right) A_{\mathrm{cav}} y_{i, \mathrm{bath}} \\
& +\max \left(-m_{\mathrm{L}, \mathrm{cav}}^{\prime \prime}, 0\right) A_{\mathrm{cav}} y_{i, \mathrm{cav}}^{*} \\
& -\left(\frac{m_{\mathrm{md}}}{\bar{t}_{\mathrm{md}}}-m_{\mathrm{L}, \mathrm{md}}^{\prime \prime} A_{\mathrm{md}}\right) \bar{\eta}_{i, \mathrm{M}, \mathrm{md}}\left(y_{i, \mathrm{bath}}-y_{i, \mathrm{md}}^{*}\right) \\
& -m_{\mathrm{L}, \mathrm{md}}^{\prime \prime} A_{\mathrm{md}} y_{i, \mathrm{bath}}-\frac{m_{\mathrm{bath}} y_{i, \mathrm{bath}}-m_{\mathrm{bath}}^{\mathrm{t}-\Delta \mathrm{t}} y_{i, \mathrm{bath}}^{\mathrm{t}-\Delta \mathrm{t}}}{\Delta t}=0 \\
& \sum_{\omega}\left[-\beta_{i, \mathrm{G}, \omega} \rho_{\mathrm{G}, \omega} A_{\omega}\left(y_{i, \mathrm{jet}}-y_{i, \omega}^{*}\right)-\max \left(m_{\mathrm{G}, \omega}^{\prime \prime}, 0\right) A_{\omega} y_{i, \mathrm{jet}}\right. \\
& \left.+\max \left(-m_{\mathrm{G}, \omega}^{\prime \prime}, 0\right) A_{\omega} y_{i, \omega}^{*}\right]+\dot{m}_{\mathrm{G}, \mathrm{in}, \mathrm{lance}} y_{i, \mathrm{in}, \mathrm{lance}}+\dot{m}_{\mathrm{G}, \mathrm{in}, \mathrm{plume} \mathrm{y}_{i, \mathrm{in}, \mathrm{plume}}} \\
& -\dot{m}_{\mathrm{G}, \mathrm{out}} y_{i, \mathrm{jet}}-\frac{m_{\mathrm{jet}} y_{i, \mathrm{jet}}-m_{\mathrm{jet}}^{\mathrm{t}-\Delta \mathrm{t}} y_{i, \mathrm{jet}}^{\mathrm{t}-\Delta \mathrm{t}}}{\Delta t}=0, \\
& \sum_{\omega}\left[-\beta_{i, \mathrm{~S}, \omega} \rho_{\mathrm{S}, \omega} A_{\omega}\left(y_{i, \mathrm{slag}}-y_{i, \omega}^{*}\right)-\max \left(m_{\mathrm{S}, \omega}^{\prime \prime}, 0\right) A_{\omega} y_{i, \text { slag }}\right. \\
& \left.+\max \left(-m_{\mathrm{S}, \omega}^{\prime \prime}, 0\right) A_{\omega} y_{i, \omega}^{*}\right]-\frac{m_{\mathrm{slag}} y_{i, \mathrm{slag}}-m_{\mathrm{slag}}^{\mathrm{t}-\Delta \mathrm{t}} y_{i, \mathrm{slag}}^{\mathrm{t}-\Delta \mathrm{t}}}{\Delta t}=0
\end{aligned}
$$

146 where $m_{\text {bath }}, m_{\text {jet }}$ and $m_{\text {slag }}$ are the masses of the steel bath, gas jet and top slag, respectively, and $147 \Delta t$ is the time step. The conservation equations for the total mass of the bulk phases (for the steel 
bath, gas jet and top slag) are defined correspondingly by summation of the mass transport terms and fluxes of species that are relevant to the bulk phase in question. Metal losses to dust were not accounted for as their effect on the composition of the steel bath is negligible.

\subsection{Conservation of heat}

Temperature increase is defined by the difference in heat generation and heat losses. While heat is generated by exothermic reactions, it is consumed by endothermic reactions as well as heat losses through the refractory lining, and top slag and exiting gas. The conservation of heat at the cavity interface is defined according to

$$
\begin{aligned}
& \underbrace{\alpha_{\mathrm{L}, \mathrm{cav}}\left(T_{\text {bath }}-T_{\text {cav }}^{*}\right)+\alpha_{\mathrm{G}, \mathrm{cav}}\left(T_{\text {jet }}-T_{\text {cav }}^{*}\right)+\alpha_{\mathrm{S}, \mathrm{cav}}\left(T_{\text {slag }}-T_{\text {cav }}^{*}\right)}_{\text {heat transport }} \\
& \underbrace{-\sum_{k=1}^{r} R_{k, \mathrm{cav}}^{\prime \prime} \Delta h_{k}=0,}_{\text {chemical reactions }}
\end{aligned}
$$

where $\alpha$ is the heat transfer coefficient, $T_{\text {bath }}$ is the temperature of the steel bath, $T_{\text {cav }}^{*}$ is the temperature of the cavity reaction interface, $T_{\text {jet }}$ is the temperature of the gas jet and $\Delta h_{k}$ is the specific reaction enthalpy of reaction $k$. The conservation of heat at the metal droplet interface was defined according to

$\underbrace{\frac{m_{\mathrm{md}}}{A_{\mathrm{md}} \bar{t}_{\mathrm{md}}} c_{\mathrm{p}, \mathrm{L}} \bar{\eta}_{\mathrm{H}, \mathrm{md}}\left(T_{\mathrm{bath}}-T_{\mathrm{md}}^{*}\right)+\alpha_{\mathrm{G}, \mathrm{md}}\left(T_{\mathrm{jet}}-T_{\mathrm{md}}^{*}\right)+\alpha_{\mathrm{S}, \mathrm{md}}\left(T_{\mathrm{slag}}-T_{\mathrm{md}}^{*}\right)}_{\text {heat transport }}$

$$
\underbrace{-\sum_{k=1}^{r} R_{k, \mathrm{md}}^{\prime \prime} \Delta h_{k}}_{\text {chemical reactions }}=0
$$

where $T_{\mathrm{md}}^{*}$ is the interfacial temperature of the metal droplets and $\bar{\eta}_{\mathrm{H}, \mathrm{md}}$ is the average microkinetic

\section{efficiency of heat transfer in the metal droplets:}

$$
\bar{\eta}_{\mathrm{H}, \mathrm{md}}=\frac{T_{\mathrm{bath}}-T_{\mathrm{md}}}{T_{\mathrm{bath}}-T_{\mathrm{md}}^{*}}=1-\exp \left(-\alpha_{\mathrm{L}, \mathrm{md}} \frac{A_{\mathrm{md}}}{m_{\mathrm{md}} c_{\mathrm{p}, \mathrm{L}}} \bar{t}_{\mathrm{md}}\right),
$$

where $T_{\mathrm{md}}$ is the temperature of the metal droplets. Employing the implicit Euler method for time 
170

171 expressed according to Eqs. 22, 23 and 24, respectively.

$$
\begin{aligned}
& -\alpha_{\mathrm{L}, \mathrm{cav}} A_{\mathrm{cav}}\left(T_{\mathrm{bath}}-T_{\mathrm{cav}}^{*}\right)-\frac{m_{\mathrm{md}}}{\bar{t}_{\mathrm{md}}} c_{\mathrm{p}, \mathrm{L}} \bar{\eta}_{\mathrm{H}, \mathrm{md}}\left(T_{\mathrm{bath}}-T_{\mathrm{md}}^{*}\right) \\
& -\sum_{\omega} \sum_{i=1}^{n} \sum_{k=1}^{r} \Gamma_{i, \mathrm{~L}} R_{k, \omega}^{\prime \prime} \bar{v}_{i, k} A_{\omega} c_{\mathrm{p}, i}\left(T_{\mathrm{bath}}-T_{\omega}^{*}\right)-q_{\text {lining }} A_{\text {lining }} \\
& -m_{\mathrm{bath}} c_{\mathrm{p}, \mathrm{bath}} \frac{T_{\mathrm{bath}}-T_{\mathrm{bath}}^{\mathrm{t}-\Delta \mathrm{t}}}{\Delta t}=0, \\
& \sum_{\omega}\left[-\alpha_{\mathrm{G}, \omega} A_{\omega}\left(T_{\mathrm{jet}}-T_{\omega}^{*}\right)-\sum_{i=1}^{n} \sum_{k=1}^{r} \Gamma_{i, \mathrm{G}} R_{k, \omega}^{\prime \prime} \bar{v}_{i, k} A_{\omega} c_{\mathrm{p}, i}\left(T_{\mathrm{jet}}-T_{\omega}^{*}\right)\right] \\
& -\dot{m}_{\mathrm{G}, \mathrm{in}, \text { lance }} \int_{T_{\mathrm{in}}}^{T_{\mathrm{jet}}} c_{\mathrm{p}, \text { lance }} \mathrm{d} T-\dot{m}_{\mathrm{G}, \mathrm{in}, \mathrm{plume}} \int_{T_{\mathrm{plume}}}^{T_{\mathrm{jet}}} c_{\mathrm{plume}} \mathrm{d} T \\
& -m_{\mathrm{jet}} c_{\mathrm{p}, \mathrm{jet}} \frac{T_{\mathrm{jet}}-T_{\mathrm{jet}}^{\mathrm{t}-\Delta \mathrm{t}}}{\Delta t}=0, \\
& \sum_{\omega}\left[-\alpha_{\mathrm{S}, \omega} A_{\omega}\left(T_{\mathrm{slag}}-T_{\omega}^{*}\right)-\sum_{i=1}^{n} \sum_{k=1}^{r} \Gamma_{i, \mathrm{~S}} R_{k, \omega}^{\prime \prime} \bar{v}_{i, k} A_{\omega} c_{\mathrm{p}, i}\left(T_{\mathrm{slag}}-T_{\omega}^{*}\right)\right] \\
& -q_{\mathrm{slag}} A_{\text {slag }}-m_{\mathrm{slag}} c_{\mathrm{p}, \mathrm{slag}} \frac{T_{\mathrm{slag}}-T_{\text {slag }}^{\mathrm{t}-\Delta \mathrm{t}}}{\Delta t}=0,
\end{aligned}
$$

172

173 where $q_{\text {lining }}$ is the heat flux through the refractory lining, $A_{\text {lining }}$ is the surface area of the refractory 174 lining, $q_{\text {slag }}$ is the heat flux through the slag and $A_{\text {slag }}$ is the cross-sectional surface area of the top 175 slag. The values of $A_{\text {lining }}$ and $A_{\text {slag }}$ are calculated based on the geometry of the simulated converter. 176 The heat flux through the refractory lining was set to $q_{\text {lining }}=12500 \mathrm{~W} / \mathrm{m}^{2}$ as in our previous work ${ }^{[29]}$. 177 The heat losses through the slag were determined on the basis of radiative heat transfer through the 178 179

$$
q_{\text {slag }}=\frac{\sigma T_{\text {slag }}^{4}}{\left[\frac{A_{\text {slag }}+A_{\text {mouth }}-2 A_{\text {slag }} F}{A_{\text {mouth }}-A_{\text {slag }} F^{2}}+\left(\frac{1}{\varepsilon_{\mathrm{S}}}-1\right)\right]},
$$

where $\sigma$ is the Stefan-Boltzmann constant, $F$ is the view factor between the top slag and the converter

mouth, $A_{\text {mouth }}$ is the cross-sectional area of the vessel mouth and $\varepsilon_{\mathrm{S}}$ is the emissivity of the slag phase, which was assumed to be $\varepsilon_{S}=0.95$. The view factor for the top slag in relation to the vessel 185

mouth is determined by ${ }^{[51]}$ 
186

where $z$ is the distance between the top slag and the vessel mouth, $r_{\text {slag }}$ is the radius of the top slag and $r_{\text {mouth }}$ is the radius of the vessel mouth. The cooling effect of the side-blown gas on the steel bath temperature is calculated separately by the earlier-proposed model for side-blowing decarburization $^{[29]}$ and is not repeated here.

\subsection{Geometry of the cavity}

The gas jet exits the lance nozzle at a supersonic velocity, but starts to spread and lose its velocity after the supersonic core. The entrainment of gases from the ambient atmosphere affects the gas jet not only by decreasing its velocity, but also by increasing its mass flow and - if the ambient temperature is higher than that of the gas jet - by increasing its temperature. ${ }^{[52]}$ Considering that the length of the supersonic region is typically 20-30 times the nozzle exit diameter at steelmaking temperatures ${ }^{[53]}$ it is apparent that the gas jet impacts the surface of the steel bath at subsonic velocity. Upon impact, the momentum of the gas jet forms a cavity on the bath surface, ${ }^{[53]}$ while the liquid steel outside the cavity is pushed towards the refractory walls of the vessel in the radial direction ${ }^{[5]}$.

Molloy ${ }^{[54]}$ distinguished three cavity modes, namely dimpling, splashing and penetrating. Dimpling refers to mere depression of the surface without droplet formation, while outwardly directed splashes start to form the edges of the depression when the mode changes to splashing. In the penetrating mode, the penetration depth is deeper and outwardly directed splashes are reduced. The different modes can also be distinguished based on the frequency and amplitude of the cavity oscillation. ${ }^{\text {[55] }}$ Figure 3 presents a schematic illustration of the gas jet impact area with a one-hole lance in the splashing mode.

\section{Figure 3}

In this work, the modelling setting was simplified by defining the reaction area between the gas jet and the steel bath as the surface area of the cavity. Because the surface of the cavity is in oscillating motion, the analysis must be based on quasi-steady state flow conditions. ${ }^{[53,56]}$ It has been suggested that chemical reactions ${ }^{[57,58]}$ and the interference of top slag ${ }^{[57]}$ do not affect the geometry of the cavity to a significant extent and on this account their effect was excluded in this work. In accordance with Cheslak et al. ${ }^{[59]}$, it was assumed that the geometry of the cavity follows the form of a paraboloid of revolution with an impact radius of $r_{\text {cav }}$ and an impinging depth of $h_{\text {cav }}$ (see Figure 3). The surface 


$$
A_{\mathrm{cav}, 1}=\frac{\pi}{6} \frac{r_{\mathrm{cav}}}{h_{\mathrm{cav}}^{2}}\left[\left(r_{\mathrm{cav}}^{2}+4 h_{\mathrm{cav}}^{2}\right)^{3 / 2}-r_{\mathrm{cav}}^{3}\right]
$$

221 For a three-hole lance, the geometry is slightly more complicated. Depending on the inclination angle of the gas jets, the gas jets may either coalesce and form only one large cavity, or penetrate the bath surface as three separate jets, whereupon each gas jet will form its own cavity. ${ }^{[61,62]}$ Even if the gas jets do not coalesce, the cavities may still coalesce provided that they are sufficiently close to each other $^{[63]}$ as shown in Figure 4. Observations with high-speed cameras ${ }^{[64]}$ suggest that the cavities remain non-coalescing when the inclination angle is greater than $10^{\circ}$. In this work, it is assumed that the gas jets do not coalesce and that the number of cavities is equal to the number of the gas jets (see Figure 4A). Therefore, the total surface area of the cavities caused by a multi-hole lance can be calculated simply by multiplying the surface area of a single cavity with the number of exit ports in the top lance: ${ }^{[52,65]}$

$$
A_{\text {cav }}=n_{\text {lance }} \times A_{\text {cav }, 1} .
$$

\section{Figure 4}

The effects of various factors on the depth and form of the cavity have been studied extensively. In this work, the correlations for the geometry of the cavity were taken from Koria and Lange ${ }^{[63]}$. The equations required for calculating the depth and radius of the cavity are given in Table $\mathbf{1}$. These are based on a dimensional analysis of experimental data on the penetration of oxygen jets in molten pig iron and pure iron-carbon alloys with both single- and multi-hole lances. ${ }^{[63]}$. It should be noted that Eq. 35 is applicable only for diatomic ideal gases (e.g. $\mathrm{O}_{2}$ or $\left.\mathrm{N}_{2}\right)$ and their mixtures. For other gas 


\subsection{Droplet generation}

254 The generation of metal droplets during top-blowing is important for steelmaking processes, because 255 it brings about a considerable increase in the interfacial area available to chemical reactions. ${ }^{[67]}$ The 256 contribution of metal droplets to the decarburization rate during top-blowing in the AOD process has 257 been acknowledged likewise ${ }^{[7,8,23,42,68-70]}$. However, foaming of the AOD slag does take place under 258 typical operating conditions. Considering the high blowing rates and high viscosity of the slag, the 259 behavior of slag should be somewhere between a void-free and an expanded slag. In such case the 260 gas void fraction would depend on the gas velocity. ${ }^{[71]}$

Different mechanisms contribute to generation of metal droplets. If the momentum flux of the topblown gas jet is sufficiently high, the liquid surface becomes unstable and the splashing of metal droplets occurs. ${ }^{[72]}$ Standish and $\mathrm{He}^{[73]}$ identified two regions of droplet generation: dropping and swarming. In the dropping region, single droplets are gradually formed and ejected. This is the mechanism of droplet generation when the gas flow rate is relatively low. When the gas flow rate is increased past a certain limit, the system reaches the swarming region and the mechanism of droplet generation changes so that not only single droplets but also large tears of liquid phase are ejected from the bath. Formation of metal droplets is also caused by side-blowing through a mechanism referred to as bubble bursting. ${ }^{[74-77]}$ This phenomenon occurs when a rising gas bubble reaches the surface of the steel and bursts creating very small metal droplets from the thin film of steel around the bubble. ${ }^{[74-77]}$ A related mechanism is the entrainment of large droplets due to jet formation, which is caused by the collapsing of the cavity after the rupture of the iron film. ${ }^{[76]}$

The secondary break-up of the metal droplets can occur due to various reasons, e.g. due to the 276 aerodynamic forces of the gas jet $^{[78]}$, impact on the slag layer ${ }^{[79]}$ or bursting resulting from 277 spontaneous CO nucleation within the droplet ${ }^{[80]}$. In the absence of suitable quantitative descriptions 278 for the break-up mechanisms and due to uncertainties related to the trajectories of the droplets, the 279 effect of the various break-up mechanisms on the droplet size distribution was not accounted for.

281 Based on the available knowledge, the lifespan of the metal droplets was assumed to consist of three 282 successive steps. At first, the metal droplets are generated at the vicinity of the cavity, from which 283 they are ejected onto a gas-metal-slag emulsion. This also includes metal droplets, which have been 284 ejected into the atmosphere and land on the emulsion. Thereafter, the metal droplets pass though the 285 emulsion layer, reacting simultaneously with gas and slag species. Finally, the metal droplets return 286 to the steel bath, where they mix with the steel bath immediately. Based on experimental findings ${ }^{[81]}$ 287 it was assumed that the initial composition of the metal droplets corresponds to the bulk composition. 
Furthermore, the metal droplets were assumed to be spherical in geometry. This assumption should

289 hold well for small droplets, ${ }^{[82]}$ which are expected to form the majority of the surface area. 290 Considering the distribution of emulsified metal droplets residing in the emulsion, their mass and surface area are obtained from the following equations:

$$
\begin{aligned}
& m_{\mathrm{md}}=\sum_{i} m_{\mathrm{md}, i}, \\
& A_{\mathrm{md}}=\sum_{i} \frac{6 m_{\mathrm{md}, i}}{d_{\mathrm{md}, i} \rho_{\mathrm{L}}},
\end{aligned}
$$

where $m_{\mathrm{md}, i}$ and $d_{\mathrm{md}, i}$ are the mass and diameter of the droplet size class $i$, respectively. As a practical matter, the droplet distribution was calculated from a diameter of $0.1 \mathrm{~mm}$ up to the diameter corresponding to the largest $99.9 \%$ by weight using a step size of $0.1 \mathrm{~mm}$. The mass of droplets in

$$
m_{\mathrm{md}, i}=f_{\mathrm{md}, i} \dot{m}_{\mathrm{md}} \min \left(t_{\mathrm{md}, i}, t\right)
$$

where $f_{\mathrm{md}, i}, \dot{m}_{\mathrm{md}}$ and $t_{\mathrm{md}, i}$ are the mass fraction of size class $i$ at place of birth, the metal droplet generation rate and the residence time of size class $i$, respectively, and $t$ is the time. The Sauter mean diameter of the metal droplets residing in the emulsion at a given moment is obtained from

$$
d_{32, \mathrm{md}}=\frac{6 m_{\mathrm{md}}}{\rho_{\mathrm{L}} A_{\mathrm{md}}}
$$

\subsubsection{Droplet generation rate}

305 The blowing number, which relates the intensity of the jet momentum to the properties of the liquid 306 steel, is defined by ${ }^{[67]}$

$$
\mathrm{N}_{\mathrm{B}}=\frac{\rho_{\mathrm{G}} u_{\mathrm{G}}^{2}}{2 \sqrt{\sigma_{\mathrm{L}} g \rho_{\mathrm{L}}}}=\frac{\eta^{2} p_{\mathrm{d}}}{\sqrt{\sigma_{\mathrm{L}} g \rho_{\mathrm{L}}}} \quad \text { where } \quad \eta=\frac{u_{\mathrm{G}}}{u_{\mathrm{j}}}
$$

where $u_{\mathrm{G}}$ denotes the critical gas velocity, $\sigma_{\mathrm{L}}$ is the surface tension of the steel, $\eta$ is a constant, $p_{\mathrm{d}}$ is the dynamic pressure of the gas jet and $u_{\mathrm{j}}$ is the axial velocity of the gas jet. The criterion for the

311 Kelvin-Helmholtz instability, and thus the onset of droplet formation, is represented with a value of $312 \mathrm{~N}_{\mathrm{B}}=1 .^{[67]}$ The experimental results of other studies suggest that $\eta$ is not independent of the lance 
313 height $^{[83-85]}$ or the gas jet angle ${ }^{[86]}$. Here, the variation of $\eta$ as a function of the gas jet angle was 314 treated in a similar fashion as by Alam et al. ${ }^{[86]}$. Making use of the concept of blowing number, 315 Subagyo et al. ${ }^{[67]}$ proposed an empirical expression for droplet generation rate $\left(\dot{m}_{\mathrm{md}}\right)$ in the splashing 316 cavity mode:

317

$$
\frac{\dot{m}_{\mathrm{md}}}{\dot{V}_{\mathrm{G}, \text { lance }}}=\frac{\left(\mathrm{N}_{\mathrm{B}}\right)^{3.2}}{\left[2.6 \times 10^{6}+2.0 \times 10^{-4}\left(\mathrm{~N}_{\mathrm{B}}\right)^{12}\right]^{0.2}} \quad R^{2}=0.97,
$$

318

where $\dot{V}_{\mathrm{G}, \text { lance }}$ is the volumetric gas flow rate through the top lance $\left(\mathrm{Nm}^{3} / \mathrm{s}\right)$. As noted by Sarkar et al. ${ }^{[87]}$ and Rout et al. ${ }^{[88]}$, Eq. 41 yields droplet generation rates which are considerably below the values estimated from plant data. According to Rout et al. ${ }^{[88]}$, one reason for the discrepancy is the fact that Eq. 41 has been derived for conditions corresponding to room temperature. Similar to Rout et al. ${ }^{[88]}$, Eq. 41 was modified such that the blowing number $\mathrm{N}_{\mathrm{B}}$ and the volumetric gas flow rate $\dot{V}_{\mathrm{G}, \text { lance }}$ are temperature corrected for the conditions at the point of impact:

$$
\frac{\dot{m}_{\mathrm{md}}}{\dot{V}_{\mathrm{G}, \text { lance }}^{\prime}}=\frac{\left(\mathrm{N}_{\mathrm{B}}^{\prime}\right)^{3.2}}{\left[2.6 \times 10^{6}+2.0 \times 10^{-4}\left(\mathrm{~N}_{\mathrm{B}}^{\prime}\right)^{12}\right]^{0.2}},
$$

where $\mathrm{N}_{\mathrm{B}}^{\prime}$ is the modified blowing number and $\dot{V}_{\mathrm{G}, \text { lance }}^{\prime}$ is the modified volumetric gas flow rate. The modified blowing number $\mathrm{N}_{\mathrm{B}}^{\prime}$ is obtained from Eq. 40 by employing the dynamic pressure at the point of impact. In this work, the dynamic pressure at the point of impact was calculated according to an experimental relationship proposed by Deo and Boom ${ }^{[52]}$ :

$$
p_{\mathrm{d}}=230 p_{0}\left(\frac{h_{\text {lance }}}{d_{\mathrm{t}}}\right)
$$

The modified gas flow rate is calculated as follows: ${ }^{[88]}$

$$
\dot{V}_{\mathrm{G}, \text { lance }}^{\prime}=\frac{p_{\mathrm{G}, \mathrm{STP}}}{p_{\mathrm{G}}} \frac{T_{\mathrm{G}}}{T_{\mathrm{G}, \mathrm{STP}}} \dot{V}_{\mathrm{G}, \text { lance }}
$$

where $p_{\mathrm{G}, \mathrm{STP}}$ is the standard pressure, $p_{\mathrm{G}}$ is the total pressure of the gas at the impact point, $T_{\mathrm{G}}$ is the temperature of the gas at the impact point and $T_{\mathrm{G}, \mathrm{STP}}$ is the standard temperature. Rout et al. ${ }^{[88]}$ suggested also that due to low lance height, the experiments conducted by Subagyo et al. ${ }^{[67]}$ did not actually correspond to splashing mode, but rather the penetrating mode of jet interaction, which is 


\subsubsection{Droplet size distribution}

347 The size distribution of the metal droplets at their place of birth was determined according to Koria and Lange ${ }^{[89]}$, who proposed a formulation based on the Rosin-Rammler-Sperling (RRS) function:

$$
R F=(0.001)^{\left(\frac{d_{\mathrm{md}, i}}{d_{\mathrm{limit}}}\right)^{n}}
$$

where $R F$ is the cumulative weight-fraction, $d_{\text {limit }}$ is the limiting droplet diameter (which corresponds to $R F=0.001$ ) and $n$ is the distribution exponent. Experimental studies indicate that the parameter $n$ is independent from the limiting diameter ${ }^{[89]}$, maximum impact pressure of the gas jet ${ }^{[89]}$ and the blowing number ${ }^{[67]}$. The reported values for the parameter $n$ vary in a relatively wide range from 1.0 to $1.828 .^{[89,90]}$ In this work, a value of $n=1.26$ was taken from Koria and Lange ${ }^{[89]}$, because it represents an arithmetic mean for a relatively large amount of data. For non-coalescing jets, the limiting diameter (in $\mathrm{m}$ ) can be obtained from ${ }^{[91]}$

$$
d_{\text {limit }}=5.513 \times 10^{-6} \times\left[10\left(\frac{d_{\mathrm{t}}^{2}}{h_{\text {lance }}^{2}}\right) p_{\mathrm{amb}}\left(1.27 \frac{p_{0}}{p_{\mathrm{amb}}}-1\right) \cos \theta\right]^{1.206},
$$

where $p_{0}$ and $p_{\mathrm{amb}}$ are the lance supply pressure (in $\mathrm{Pa}$ ) and the ambient pressure (in $\mathrm{Pa}$ ), respectively. This expression suggests that droplet sizes increase with increasing lance supply pressure and decreasing lance height, and thus it appears to be in accordance with other studies ${ }^{[67,90,92]}$. Modifying the expression presented by Deo et al. ${ }^{[93]}$ to a more general form, the mass fraction of size

$$
f_{\mathrm{md}, i}=-\ln (0.001) n R F \frac{d_{\mathrm{md}, i}^{n-1}}{d_{\mathrm{limit}}^{n}} .
$$


367 The average residence time of the metal droplets is obtained from

$$
\bar{t}_{\mathrm{md}}=\frac{m_{\mathrm{md}}}{\dot{m}_{\mathrm{md}}} .
$$

According to the results available in the literature, the average residence time of the droplets increases with an increasing top gas flow rate ${ }^{[94]}$ and decreasing droplet size $\mathrm{e}^{[94,95]}$. As shown by Urquhart and Davenport ${ }^{[96]}$, the size distribution of the metal droplets in the emulsion is shifted towards smaller droplets than the distribution of the generated droplets. The residence time of an individual droplet in the emulsion can be defined as the ratio of the trajectory length to the average velocity. ${ }^{[67]}$ However, for the simplified setting considered in this work, it is more convenient to define the residence time

$$
t_{\mathrm{md}, i}=\kappa \frac{h_{\mathrm{em}}}{u_{\mathrm{md}, i}}
$$

where $h_{\mathrm{em}}$ is the height of the emulsion layer and $u_{\mathrm{md}, i}$ is the terminal velocity of size class $i$. Because the residence time approaches infinity as the droplet diameter approaches zero, the residence time was limited to $t_{\mathrm{md}, i} \leq 60 \mathrm{~s}$ in order to avoid computational problems. The terminal velocity of the metal droplets in the emulsion was defined in three Reynolds ranges according to the equations

Moreover, it was assumed that all droplets of the same size class have the same residence time. The

$$
h_{\mathrm{em}}=\frac{m_{\mathrm{em}}}{A_{\mathrm{slag}} \rho_{\mathrm{em}}}=\frac{m_{\mathrm{em}}}{\left(A_{\mathrm{bath}}-n_{\text {lance }} \times \pi r_{\mathrm{cav}}^{2}\right) \rho_{\mathrm{em}}},
$$

where $m_{\mathrm{em}}$ is the mass of the emulsion, $A_{\text {slag }}$ is the surface area of the top slag layer residing around the cavities, $\rho_{\mathrm{em}}$ is the density of the emulsion and $A_{\text {bath }}$ is the cross-sectional area of the steel bath.

$$
\rho_{\mathrm{em}}=\rho_{\mathrm{L}} \phi_{\mathrm{L}}+\rho_{\mathrm{S}}\left(1-\phi_{\mathrm{L}}\right)
$$




$$
\phi_{\mathrm{L}}=\frac{V_{\mathrm{L}}}{V_{\mathrm{L}}+V_{\mathrm{G}}+V_{\mathrm{S}}} \quad \text { where } \quad V_{\mathrm{G}}=\frac{\phi_{\mathrm{G}}}{1-\phi_{\mathrm{G}}}\left(V_{\mathrm{L}}+V_{\mathrm{S}}\right)
$$

395

400

$$
\begin{aligned}
& \beta=\operatorname{Sh} \frac{D}{L}, \\
& \alpha=\operatorname{Nu} \frac{\lambda}{L},
\end{aligned}
$$

406

$$
\mathrm{Sh}= \begin{cases}1.41 \mathrm{Re}^{0.51} \mathrm{Sc}^{0.33} & \text { when } 2 \times 10^{3} \leq \mathrm{Re} \leq 3 \times 10^{4} \\ 0.41 \mathrm{Re}^{0.75} \mathrm{Sc}^{0.33} & \text { when } 3 \times 10^{4} \leq \mathrm{Re} \leq 2 \times 10^{5}\end{cases}
$$

where $V_{\mathrm{L}}, V_{\mathrm{G}}$ and $V_{\mathrm{S}}$ denote the volumes of metal, gas and slag phases in emulsion, respectively. The volume-fraction of gas in the emulsion was solved numerically from the correlation proposed by Gou

$$
\frac{\phi_{\mathrm{G}}^{2}}{1-\phi_{\mathrm{G}}}=0.91 u_{\mathrm{s}}^{0.57}
$$

\subsection{Mass and heat transfer coefficients}

where Sh is the Sherwood number, $D$ is the mass diffusivity, $L$ is the characteristic length, Nu is the Nusselt number and $\lambda$ is the heat conductivity. A detailed treatment of these parameters is provided in the following subsections.

\subsubsection{Cavity interface}

At the cavity interface, the cavity radius $\left(r_{\text {cav }}\right)$ was employed as the characteristic length. The mass transfer correlations employed for the gas jet were taken from Oeters ${ }^{[99]}$. These correlations are based on the experimental data published by Lohe ${ }^{[100]}$ and can be represented as follows:

416 where Re is the Reynolds number and Sc is the Schmidt number. Similarly to Dogan et al. ${ }^{[101]}$, the 
417 values of Re and Sc were defined in relation to the properties of the gas film at the impact surface:

418

$$
\begin{aligned}
& \operatorname{Re}=\frac{u_{\mathrm{G}} r_{\mathrm{cav}} \rho_{\mathrm{G}}}{\mu_{\mathrm{G}}}, \\
& \mathrm{Sc}=\frac{\mu_{\mathrm{G}}}{\rho_{\mathrm{G}} D_{\mathrm{G}}},
\end{aligned}
$$

419

420 where $u_{\mathrm{G}}$ is the critical gas velocity, $\mu_{\mathrm{G}}$ is the dynamic viscosity of the gas film and $\rho_{\mathrm{G}}$ is the density 421 of the gas film. The critical gas velocity $\left(u_{\mathrm{G}}\right)$ is calculated from the free axial velocity of the gas jet

$422\left(u_{\mathrm{j}}\right)$. For the metal phase in contact with gas jet, the turbulent diffusion boundary layer thickness and

423 the corresponding Sherwood number were defined according to Eqs. 60 and 61, respectively. ${ }^{[99]}$ 424

$$
\begin{aligned}
& \delta_{\mathrm{N}}=\sqrt{\frac{D_{\mathrm{L}} \sigma_{\text {equiv }}}{0.41 \rho_{\mathrm{L}} u_{\tau}^{3}}}, \\
& \mathrm{Sh}=\frac{r_{\mathrm{cav}}}{2 \delta_{\mathrm{N}}},
\end{aligned}
$$

where $u_{\tau}$ is the turbulent shear stress velocity and $\sigma_{\text {equiv }}$ is the equivalent surface tension. The

thickness of the thermal boundary layer $\left(\delta_{\mathrm{Pr}}\right)$ can be obtained from Eq. 60 by replacing the mass

$$
u_{\tau}=\sqrt{\frac{\rho_{\mathrm{G}}}{\rho_{\mathrm{L}}}} u_{\mathrm{j}} .
$$

435 The heat transfer coefficients for gas, metal and slag phases were derived from the mass transfer 436 correlations according to the analogue of heat and mass transfer by replacing the Sherwood number 437 (Sh) and the Schmidt number $(\mathrm{Sc})$ with the Nusselt number $(\mathrm{Nu})$ and the Prandtl number $(\mathrm{Pr})$, 
440 At the metal droplet interface, the mass and heat transfer coefficients were calculated by employing 441 the Sauter mean diameter of the metal droplets $\left(d_{32, \mathrm{md}}\right)$ as the characteristic length. The mass transfer 442 coefficient mass of the gas phase in contact with the metal droplets can be calculated from the 443 Steinberger and Treybal ${ }^{[103]}$ correlation, which accounts for the effects of both natural and forced 444 convection:

445

$$
\begin{aligned}
& \mathrm{Sh}=\mathrm{Sh}_{0}+0.347\left(\mathrm{ReSc}^{1 / 2}\right)^{0.62}, \\
& \mathrm{Sh}_{0}=\left\{\begin{array}{ll}
2+0.569(\overline{\mathrm{GrSc}})^{1 / 4} & \text { for } \overline{\mathrm{GrSc}}<10^{8} \\
2+0.0254(\overline{\mathrm{GrS}})^{1 / 2} \mathrm{Sc}^{0.244} & \text { for } \overline{\mathrm{GrSc}}>10^{8}
\end{array},\right.
\end{aligned}
$$

446

447 where $\overline{\mathrm{Gr}}$ is the mean Grashof number. The mean Grashof number $(\overline{\mathrm{Gr}})$, the Reynolds number $(\mathrm{Re})$ 448 and the Schmidt number (Sc) were defined as follows:

449

$$
\begin{aligned}
& \overline{\mathrm{Gr}}=\mathrm{Gr}_{\mathrm{M}}+\mathrm{Gr}_{\mathrm{H}}\left(\frac{\mathrm{Sc}}{\mathrm{Pr}}\right)^{1 / 2}, \\
& \operatorname{Re}=\frac{u_{\mathrm{G}} d_{32, \mathrm{md}} \rho_{\mathrm{G}}}{\mu_{\mathrm{G}}}, \\
& \mathrm{Sc}=\frac{\mu_{\mathrm{G}}}{\rho_{\mathrm{G}} D_{\mathrm{G}}},
\end{aligned}
$$

where $\mathrm{Gr}_{\mathrm{M}}$ is the Grashof number for mass transfer, $\mathrm{Gr}_{\mathrm{H}}$ is the Grashof number for heat transfer and 451 Pr is the Prandtl number. Here, $\mathrm{Gr}_{\mathrm{M}}, \mathrm{Gr}_{\mathrm{H}}$ and Pr were defined according to Eqs. 68, 69 and 70, respectively. It should be noted that the value of $\mathrm{Gr}_{\mathrm{M}}$ depends on the species in question.

453

$$
\begin{aligned}
& \operatorname{Gr}_{\mathrm{M}, i}=\frac{g \rho_{\mathrm{G}} d_{32, \mathrm{md}}^{3}\left(y_{i, \mathrm{md}}^{*} \rho_{\mathrm{G}, \mathrm{md}}-\mathrm{y}_{i, \mathrm{jet}} \rho_{\mathrm{G}, \mathrm{jet}}\right)}{\mu_{\mathrm{G}}^{2}}, \\
& \mathrm{Gr}_{\mathrm{H}}=\frac{g \rho_{\mathrm{G}}^{2} d_{32, \mathrm{md}}^{3}\left(T_{\mathrm{md}}^{*}-T_{\mathrm{jet}}\right)}{T_{\mathrm{G}} \mu_{\mathrm{G}}^{2}}, \\
& \operatorname{Pr}=\frac{c_{\mathrm{p}, \mathrm{G}} \mu_{\mathrm{G}}}{\lambda_{\mathrm{G}}}
\end{aligned}
$$

455 where $c_{\mathrm{p}, \mathrm{G}}$ is the specific heat capacity of the gas phase and $\lambda_{\mathrm{G}}$ is the heat conductivity of the gas 456 phase. The heat transfer coefficient was calculated with the help of Eqs. 63 and 64 by replacing Sh, 
$\overline{\mathrm{Gr}}$ and Sc with $\mathrm{Nu}, \mathrm{Gr}_{\mathrm{H}}$ and $\mathrm{Pr}$, respectively. It is known that mass transfer within small metal droplets takes place almost entirely by diffusion, while larger droplets may exhibit uninhibited circulatory flow. ${ }^{[99,104]}$ In this work, it was assumed that only creeping laminar circulation takes place within the metal droplets. Therefore, the mass transfer coefficient can be calculated according to the Kronig and Brink ${ }^{[105]}$ solution, which can be expressed in terms of the Sherwood number as 462 follows: ${ }^{[106]}$

463

$$
\mathrm{Sh}=\frac{32}{3} \frac{\sum_{i=1}^{\infty} A_{i}^{2} \lambda_{i} \exp \left(-16 \lambda_{i} \mathrm{Fo}_{\mathrm{M}}\right)}{\sum_{i=1}^{\infty} A_{i}^{2} \exp \left(-16 \lambda_{i} \mathrm{Fo}_{\mathrm{M}}\right)}
$$

464

465

466

467

468

469

470

471

472

473

474

475

476

477

478

479

where $\mathrm{Fo}_{\mathrm{M}}$ is the Fourier number for mass transfer. The first seven values for the parameters $A_{i}$ and $\lambda_{i}$ were taken from the literature ${ }^{[107]}$ and provide a sufficient convergence. Despite its limited range of theoretical applicability, experimental studies have shown that the Kronig and Brink solution gives a reasonably good prediction of the mass transfer coefficient even at Reynolds numbers well above those corresponding to creeping flow. ${ }^{[108]}$ Employing the average residence time of the metal droplets $\left(\bar{t}_{\mathrm{md}}\right)$ as the characteristic time, the Fourier number for mass transfer can be defined according to

$$
\mathrm{Fo}_{\mathrm{M}}=\frac{4 D_{\mathrm{L}} \bar{t}_{\mathrm{md}}}{d_{32, \mathrm{md}}^{2}}
$$

The corresponding Fourier number for heat transfer $\left(\mathrm{Fo}_{\mathrm{H}}\right)$ is obtained from Eq. 72 by replacing mass diffusivity with thermal diffusivity. Thus the heat transfer coefficient for the metal droplets is obtained by replacing $\mathrm{Sh}$ and $\mathrm{Fo}_{\mathrm{M}}$ with $\mathrm{Nu}$ and $\mathrm{Fo}_{\mathrm{H}}$, respectively. The mass transfer in the slag phase surrounding the metal droplets was calculated according to Eq. 73, which is valid for fluid spheres in creeping flow. ${ }^{[109]}$

$$
\begin{aligned}
& \operatorname{Sh}=0.65\left(\frac{\mu_{\mathrm{S}}}{\mu_{\mathrm{S}}+\mu_{\mathrm{L}}}\right)^{1 / 2} \operatorname{Re}^{1 / 2} \mathrm{Sc}^{1 / 2} \\
& =0.65\left(\frac{\mu_{\mathrm{S}}}{\mu_{\mathrm{S}}+\mu_{\mathrm{L}}}\right)^{1 / 2}\left(\frac{\rho_{\mathrm{S}} \bar{u}_{\mathrm{md}} d_{32, \mathrm{md}}}{\mu_{\mathrm{S}}}\right)^{1 / 2}\left(\frac{\mu_{\mathrm{S}}}{\rho_{\mathrm{S}} D_{\mathrm{S}}}\right)^{1 / 2},
\end{aligned}
$$

where $\bar{u}_{\text {md }}$ is the average terminal velocity of the metal droplets in the emulsion. The heat transfer coefficient for the slag phase in contact with the metal droplets was obtained using the analogue of heat and mass transfer by replacing Sh and Sc with $\mathrm{Nu}$ and Pr, respectively. 


\subsection{Thermodynamic properties}

484 All the thermodynamic properties were defined at the composition and temperature of the reaction 485 interface in question. The equilibrium constants are defined by

486

$$
K=\exp \left(-\frac{\Delta G^{\circ}}{R T^{*}}\right) \text { where } \Delta G^{\circ}=\Delta H^{\circ}-T^{*} \Delta S^{\circ}
$$

487

488

489

490

491

$$
\begin{aligned}
\Delta H^{\circ} & =\sum_{i=1}^{n} v_{i} H_{i}^{\circ}, \\
\Delta S^{\circ} & =\sum_{i=1}^{n} v_{i} S_{i}^{\circ},
\end{aligned}
$$

\section{(75)}

(76)
492

where $v_{i}, H_{i}^{\circ}$ and $S_{i}^{\circ}$ are the stoichiometric coefficient, enthalpy and entropy of species $i$. The values of $H_{i}^{\circ}$ and $S_{i}^{\circ}$ at temperature $T$ were calculated as follows:

$$
\begin{aligned}
& H^{\circ}(T)=H_{298.15}^{\circ}+\int_{298.15}^{T} C_{\mathrm{p}} \mathrm{d} T+H_{\mathrm{tr}, T}^{\circ}+H_{\mathrm{dis}}^{\circ} \\
& S^{\circ}(T)=S_{298.15}^{\circ}+\int_{298.15}^{T} \frac{C_{\mathrm{p}}}{T} \mathrm{~d} T+S_{\mathrm{tr}, T}^{\circ}+S_{\mathrm{dis}}^{\circ}
\end{aligned}
$$

where $H_{298.15}^{\circ}$ is the enthalpy at $298.15 \mathrm{~K}\left(25^{\circ} \mathrm{C}\right), C_{\mathrm{p}}$ is the molar heat capacity, $H_{\mathrm{tr}}^{\circ}$ is the total enthalpy of phase transformations from $298.15 \mathrm{~K}\left(25^{\circ} \mathrm{C}\right)$ to $T, H_{\text {dis }}^{\circ}$ is the enthalpy of dissolution, $S_{298.15}^{\circ}$ is the entropy at $298.15 \mathrm{~K}\left(25^{\circ} \mathrm{C}\right), S_{\mathrm{tr}}^{\circ}$ is the total entropy of phase transformations from $298.15 \mathrm{~K}\left(25{ }^{\circ} \mathrm{C}\right)$ to $T$, and $S_{\text {dis }}^{\circ}$ is the entropy of dissolution. The enthalpies $H^{\circ}$ and entropies $S^{\circ}$ correspond to the following standard states: the Henrian standard state for the species dissolved in the steel bath and the Raoultian standard state for the gas and slag species. For the dissolved species, the relevant values of $H_{\text {dis }}^{\circ}$ and $S_{\text {dis }}^{\circ}$ were obtained from Sigworth and Elliott ${ }^{[110]}$, while for the gas and slag species $H_{\text {dis }}^{\circ}$ and $S_{\text {dis }}^{\circ}$ were set to zero. The molar heat capacity at temperature $T$ is solved from the Shomate equation ${ }^{[111]}$ : 


$$
C_{\mathrm{p}}=A+B \cdot 10^{-3} T+C \cdot 10^{5} T^{-2}+D \cdot 10^{-6} T^{2},
$$

where $A, B, C$ and $D$ are fitting parameters applicable to a certain temperature interval. A comprehensive database of the Shomate equation parameters was taken from HSC Chemistry ${ }^{[11]}$.

The partial pressures of the gaseous species can be calculated from the ideal gas law based on the 511 total gas pressure at the reaction interface. The Henrian activity coefficients of the species in the 512 liquid metal phase were calculated with the Unified Interaction Parameter (UIP) formalism ${ }^{[12]}$ :

$$
\ln \gamma_{i}^{\mathrm{H}}=\ln \frac{\gamma_{i}^{\mathrm{R}}}{\gamma_{i}^{\circ}}=-0.5 \sum_{j=1}^{n} \sum_{k=1}^{n} \varepsilon_{j}^{k} x_{j}^{*} x_{k}^{*}+\sum_{j=1}^{n} \varepsilon_{i}^{j} x_{j}^{*},
$$

515 where $\gamma_{i}^{\mathrm{H}}$ is the Henrian activity coefficient of species $i, \gamma_{i}^{\mathrm{R}}$ is the Raoultian activity coefficient of species $i, \gamma_{i}^{\circ}$ is the activity coefficient of species $i$ at infinite dilution, $\varepsilon$ is the first-order molar interaction parameter and $x^{*}$ is the molar fraction at the reaction interface. The employed first-order molar interaction parameters are given in Table 2.

Table 2

$$
\text { Refs. }{ }^{[113][114][115][116][110]}
$$

The activity coefficients of the slag species were calculated according to the model employed by Wei

$$
\begin{aligned}
& \log _{10} \gamma_{\mathrm{FeO}}^{\mathrm{R}}=\frac{\varepsilon_{1}}{T^{*}}\left(x_{\mathrm{CaO}}^{*}+x_{\mathrm{MgO}}^{*}\right)\left(x_{\mathrm{SiO}_{2}}^{*}+0.25 x_{\mathrm{AlO} 1.5}^{*}\right) \\
& +\frac{\varepsilon_{2}}{T^{*}} x_{\mathrm{MnO}}^{*}\left(x_{\mathrm{SiO}_{2}}^{*}+0.45 x_{\mathrm{CrO} 1.5}^{*}\right)+\frac{\varepsilon_{3}}{T^{*}} x_{\mathrm{AlO} 1.5}^{*} x_{\mathrm{SiO}_{2}}^{*} \\
& +\frac{\varepsilon_{4}}{T^{*}} x_{\mathrm{MnO}}^{*} x_{\mathrm{AlO} 1.5}^{*}+\frac{\varepsilon_{5}}{T^{*}} x_{\mathrm{CrO} 1.5}^{*} x_{\mathrm{SiO}_{2}}^{*}, \\
& \log _{10} \gamma_{\mathrm{Cr}_{2} \mathrm{O}_{3}}^{\mathrm{R}}=\log _{10} \gamma_{\mathrm{FeO}}^{\mathrm{R}}-\frac{\varepsilon_{6}}{T^{*}}\left(x_{\mathrm{CaO}}^{*}+x_{\mathrm{MgO}}^{*}\right)-\frac{\varepsilon_{7}}{T^{*}} x_{\mathrm{MnO}}^{*}-\frac{\varepsilon_{5}}{T^{*}} x_{\mathrm{SiO}_{2}}^{*}, \\
& \log _{10} \gamma_{\mathrm{MnO}}^{\mathrm{R}}=\log _{10} \gamma_{\mathrm{FeO}}^{\mathrm{R}}-\frac{\varepsilon_{2}}{T^{*}}\left(x_{\mathrm{SiO}_{2}}^{*}+0.45 x_{\mathrm{CrO} 1.5}^{*}\right)-\frac{\varepsilon_{4}}{T^{*}} x_{\mathrm{AlO} 1.5}^{*}, \\
& \log _{10} \gamma_{\mathrm{SiO} O_{2}}^{\mathrm{R}}=\log _{10} \gamma_{\mathrm{FeO}}^{\mathrm{R}}-\frac{\varepsilon_{1}}{T^{*}}\left(x_{\mathrm{CaO}}^{*}+x_{\mathrm{MgO}}^{*}\right)-\frac{\varepsilon_{2}}{T^{*}} x_{\mathrm{MnO}}^{*} \\
& -\frac{\varepsilon_{3}}{T^{*}} x_{\mathrm{AlO} 1.5}^{*}-\frac{\varepsilon_{5}}{T^{*}} x_{\mathrm{CrO} 1.5}^{*},
\end{aligned}
$$



applicable for the early period of refining were employed. Similar to Wei and Zhu, ${ }^{[21]}$ it was assumed that $a_{\mathrm{Cr}_{2} \mathrm{O}_{3}}^{\mathrm{R}}=1$ if the interfacial $\mathrm{Cr}_{2} \mathrm{O}_{3}$ content is greater than the maximum solubility of $\mathrm{Cr}_{2} \mathrm{O}_{3}$ in the

\subsection{Physical properties}

535 The physical properties of the steel and slag phases were estimated at the temperature of the reaction 536 interface, while the properties of the gas phase were defined at gas film temperature, which was 537 approximated as ${ }^{[117]}$

where $T^{*}$ is the temperature of reaction interface and $T_{\text {jet }}$ is the temperature of the gas jet. The effective mass diffusivity was defined for each species in the metal phase as the interdiffusivity in liquid iron, while only one effective diffusivity value was assigned for the gas and slag phases. Where by an Arrhenius type relationship ${ }^{[118]}$. In order to account for the effect of pressure and temperature, the mass diffusivity of the gaseous species was treated according to ${ }^{\text {[29] }}$

$$
D_{\mathrm{G}}=D_{\mathrm{G}, \mathrm{eff}} \times\left(\frac{T_{\mathrm{G}}}{T_{\text {ref }}}\right)^{1.5}\left(\frac{p_{\text {ref }}}{p_{\mathrm{G}}}\right)
$$

where $D_{\mathrm{G}, \text { eff }}$ is the effective mass diffusivity at $T_{\text {ref }}$ and $p_{\text {ref }}, T_{\text {ref }}$ is the reference temperature, $p_{\text {ref }}$ is the reference pressure and $p_{\mathrm{G}}$ is the total gas pressure. The pressure changes in the gas jet are small enough to be neglected ${ }^{[72]}$ and hence the total gas pressure was taken as equal to the atmospheric pressure at both reaction interfaces. The treatment of other physical properties is summarized in Table 4 along with their corresponding references.

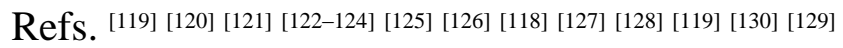

During decarburization, the top slag consists of a molten slag phase saturated with chromium oxide and a solid chromium oxide phase. ${ }^{[131]}$ For this reason, it is necessary to consider the effect of solid 
particles on the viscosity of the top slag. The viscosity of the liquid part $\left(\mu_{\mathrm{S}(1)}\right)$ was calculated using

560 the viscosity model proposed by Forsbacka et al. ${ }^{[125]}$, which is an extension of the modified Urbain 561 model ${ }^{[132]}$ for the $\mathrm{Al}_{2} \mathrm{O}_{3}-\mathrm{CaO}-\mathrm{CrO}-\mathrm{Cr}_{2} \mathrm{O}_{3}$-' $\mathrm{FeO}$ '- $\mathrm{MgO}-\mathrm{SiO}_{2}$ system. The effective viscosity of the top 562 slag was determined as relative to the viscosity of the liquid slag phase:

$$
\mu_{\mathrm{S}}=\mu_{\mathrm{S}(\mathrm{l})} \mu_{\mathrm{S}, \mathrm{rel}}
$$

The relative viscosity $\mu_{\mathrm{S} \text {,rel }}$ was calculated according to the equation proposed by Thomas ${ }^{[126]}$. Figure 5 provides a comparison of the Thomas ${ }^{[126]}$ equation with other relative viscosity equations available in the literature ${ }^{[133-139]}$. With the exception of the Einstein equation ${ }^{[133]}$, the equations produce similar results up to a solid volume fraction of 0.3 , but begin to diverge as the solid volume fraction approaches unity. The solid volume fraction was calculated as a function of $\mathrm{Cr}_{2} \mathrm{O}_{3}$ content as shown in the second part of this work ${ }^{[44]}$.

Figure 5 Refs. ${ }^{[126,133-139]}$

\subsection{Numerical solution}

The objective of the numerical solution routine is to minimize the error in free variables, while minimizing the error in thermodynamic equilibrium at the reaction interfaces. The thermodynamic equilibrium at the reaction interface and the mass transfer onto and from the interface are solved simultaneously. However, conservation of mass and heat are solved successively. Using small time steps, this does not cause significant inaccuracy, but greatly improves the numerical stability. The flowchart of the model is shown in Figure 6.

Figure 6 approximates the solution by its tangent line. ${ }^{[140]}$ For a set of non-linear equations the Newton's

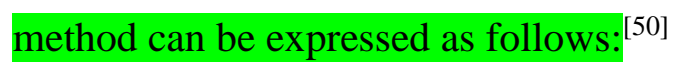

$$
J \times \partial x=-f,
$$

where $\mathbf{J}$ is the Jacobian matrix of the system with respect to all free variables, $\mathbf{\partial x}$ is the correction vector and $\mathbf{f}$ is the residual vector, which approaches zero asymptotically during the iteration. The 
system of linear equations defined by Eq. 88 is solved by Gauss-Jordan elimination. During iteration, the vector of free variables is updated similar to the relaxed Newton's method. The calculation procedure is repeated until the numerical error is sufficiently small or the maximum number of iterations is exceeded. The error in the residual vector $\mathbf{f}$ is measured using the $l^{2}$-norm, which is the Euclidian length of the correction vector:

595

$$
\|\Delta \mathbf{x}\|_{2}=\sqrt{\sum_{i} \Delta x_{i}^{2}} .
$$

As stated earlier, one of the main assumptions of the model is that the reaction interfaces reach their mass-transfer constrained equilibrium composition at every instant. During the numerical solution, the interfacial composition asymptotically approaches the composition dictated by the equilibrium constants, provided that the forward reaction rate coefficients $\left(k_{\mathrm{f}}\right)$ are sufficiently large. In order to assess the fulfilment of the equilibrium assumption, the concept of equilibrium number is introduced:

$$
\mathrm{E}=\left|1-\frac{Q}{K}\right|
$$

$$
Q=\frac{\sum_{p} a_{p}^{v_{p}}}{\sum_{r} a_{r}^{v_{r}}}
$$

where $p$ and $r$ denote reaction products and reactants, respectively. By definition, $Q=K$ at equilibrium. Because $Q \rightarrow K$ as $k_{\mathrm{f}} \rightarrow \infty$, it follows that $\mathrm{E} \rightarrow 0$ as $k_{\mathrm{f}} \rightarrow \infty$. Owing to these properties, the equilibrium number provides a practical measure of the relative fulfilment of the equilibrium assumption. As a preliminary setting the maximum allowed error was set to $\mathrm{E}=0.1 \%$ for all the studied reactions. During numerical solution, the forward reaction rate coefficients are increased periodically until the equilibrium numbers of all the reactions are below the maximum allowed error. A typical calculation time per time step is in the order of few seconds using a desktop PC (3.4 GHz).

\section{Conclusions}

The objective of this work was to develop a fast numerical model for the reactions that occur during top-blowing in the AOD process. More specifically, the aim was to create a model that considers 
618 reactions both between the top-blown gas and the steel bath and between metal droplets and top slag.

619 Employing the categorization proposed by Ding et al. ${ }^{[41]}$, the model derived in this work can be 620 classified as a complex process mechanism model, because it emphasizes the local thermodynamic 621 equilibrium and local heat and mass transfer characteristics. In the second part of this work, ${ }^{[44]}$ the 622 model is validated with heats from a full size AOD vessel. In the future, the combined top- and side623 blowing stage of the AOD process can be simulated as a combination of the top-blowing model 624 derived in this work and the side-blowing model proposed earlier by Järvinen et al. ${ }^{[29]}$.

\section{Acknowledgements}

626 This research has been conducted within the framework of the DIMECC SIMP research program.

627 Outokumpu Stainless Oy, the Finnish Funding Agency for Technology and Innovation (TEKES), the 628 Graduate School in Chemical Engineering (GSCE), the Academy of Finland (projects 258319 and 629 26495), the Finnish Foundation for Technology Promotion, the Finnish Science Foundation for 630 Economics and Technology, and the Tauno Tönning Foundation are gratefully acknowledged for 631 funding this work. The first author thanks Professor Herbert Pfeifer for the possibility to conduct part 632 of the research at RWTH Aachen University. In addition, Professor Rauf Hürman Eriç, Kevin 633 Christmann and Tim Haas are acknowledged for their valuable comments on this manuscript.

634 Nomenclature

$\begin{array}{llll}635 & \text { Symbols } & \\ 636 & a & \text { Activity } \\ 637 & A & \text { Surface area }\left[\mathrm{m}^{2}\right] \\ 638 & A_{i} & \text { Parameter of the Kronig-Brink solution } \\ 639 & C_{\mathrm{p}} & \text { Molar heat capacity at constant pressure }[\mathrm{J} /(\mathrm{mol} \cdot \mathrm{K})] \\ 640 & c_{\mathrm{p}} & \text { Specific heat capacity at constant pressure }[\mathrm{J} /(\mathrm{kg} \cdot \mathrm{K})] \\ 641 & d_{\mathrm{t}} & \text { Nozzle throat diameter }[\mathrm{m}] \\ 642 & d_{\text {limit }} & \text { Fineness parameter of the RRS distribution }[\mathrm{m}] \\ 643 & d_{32, \mathrm{md}} & \text { Sauter mean diameter of the metal droplets }[\mathrm{m}] \\ 644 & D & \text { Diffusion coefficient }\left[\mathrm{m}^{2} / \mathrm{s}\right] \\ 645 & f_{i} & \text { Mass fraction of size class } i \text { at place of birth } \\ 646 & \mathbf{f} & \text { Residual vector } \\ 647 & g & \text { Standard gravity }\left[\mathrm{m} / \mathrm{s}^{2}\right] \\ 648 & \Delta G^{\circ} & \text { Change in standard } \mathrm{Gibbs} \text { free energy of reaction }[\mathrm{J} / \mathrm{mol}] \\ 649 & \Delta G_{\text {tot }} & \text { Change in total Gibbs free energy }[\mathrm{J} / \mathrm{mol}]\end{array}$




\begin{tabular}{|c|c|c|}
\hline 650 & $h_{\text {cav }}$ & Depth of the cavity $[\mathrm{m}]$ \\
\hline 651 & $h_{\text {lance }}$ & Distance of the top lance from the surface of the steel bath [m] \\
\hline 652 & $H^{\circ}$ & Standard enthalpy $[\mathrm{J} / \mathrm{mol}]$ \\
\hline 653 & $\Delta H^{\circ}$ & Change in standard reaction enthalpy $[\mathrm{J} / \mathrm{mol}]$ \\
\hline 654 & $\mathbf{J}$ & Jacobian matrix \\
\hline 655 & $J_{\text {eff }}$ & Droplet generation rate multiplication factor \\
\hline 656 & $k_{\mathrm{f}}$ & Forward reaction rate coefficient \\
\hline 657 & $K$ & Equilibrium constant \\
\hline 658 & $L$ & Characteristic length $[\mathrm{m}]$ \\
\hline 659 & $m$ & Mass $[\mathrm{kg}]$ \\
\hline 660 & $\dot{m}_{\mathrm{md}}$ & Metal droplet generation rate $[\mathrm{kg} / \mathrm{s}]$ \\
\hline 661 & $\dot{m}_{\mathrm{md}, \mathrm{eff}}$ & Effective metal droplet generation rate $[\mathrm{kg} / \mathrm{s}]$ \\
\hline 662 & $M$ & Molar mass $[\mathrm{kg} / \mathrm{mol}]$ \\
\hline 663 & $n_{\text {lance }}$ & Number of exit ports in a nozzle \\
\hline 664 & $n$ & Distribution exponent of the RRS distribution \\
\hline 665 & $p$ & Partial pressure \\
\hline 666 & $p_{\text {cav }}$ & Arc length of the cavity $[\mathrm{m}]$ \\
\hline 667 & $p_{\mathrm{amb}}$ & Ambient pressure $[\mathrm{Pa}]$ \\
\hline 668 & $p_{0}$ & Stagnation pressure at upstream part of the top lance $[\mathrm{Pa}]$ \\
\hline 669 & $r_{\text {cav }}$ & Top radius of the cavity $[\mathrm{m}]$ \\
\hline 670 & $R$ & Gas constant $[\mathrm{J} /(\mathrm{mol} \cdot \mathrm{K})]$ \\
\hline 671 & $R^{\prime \prime}$ & Reaction rate $\left[\mathrm{kg} /\left(\mathrm{m}^{2} \cdot \mathrm{s}\right)\right]$ \\
\hline 672 & $R^{2}$ & Correlation coefficient \\
\hline 673 & $R F$ & Cumulative weight-fraction \\
\hline 674 & $S^{\circ}$ & Standard entropy $[\mathrm{J} /(\mathrm{mol} \cdot \mathrm{K})]$ \\
\hline 675 & $\Delta S^{\circ}$ & Change in standard reaction entropy $[\mathrm{J} /(\mathrm{mol} \cdot \mathrm{K})]$ \\
\hline 676 & $t_{\mathrm{md}, i}$ & Residence time of metal droplet size class $i[\mathrm{~s}]$ \\
\hline 677 & $\bar{t}_{\mathrm{md}}$ & Average residence time of the metal droplets [s] \\
\hline 678 & $T$ & Temperature [K] \\
\hline 679 & $T^{*}$ & Interfacial temperature $[\mathrm{K}]$ \\
\hline 680 & $u_{\mathrm{G}}$ & Critical gas velocity $[\mathrm{m} / \mathrm{s}]$ \\
\hline 681 & $u_{\mathrm{j}}$ & Axial velocity of the gas jet $[\mathrm{m} / \mathrm{s}]$ \\
\hline 682 & $u_{\mathrm{md}, i}$ & Terminal velocity of metal droplet size class $i[\mathrm{~m} / \mathrm{s}]$ \\
\hline 683 & $\bar{u}_{\mathrm{md}}$ & Average terminal velocity of the metal droplets $[\mathrm{m} / \mathrm{s}]$ \\
\hline
\end{tabular}




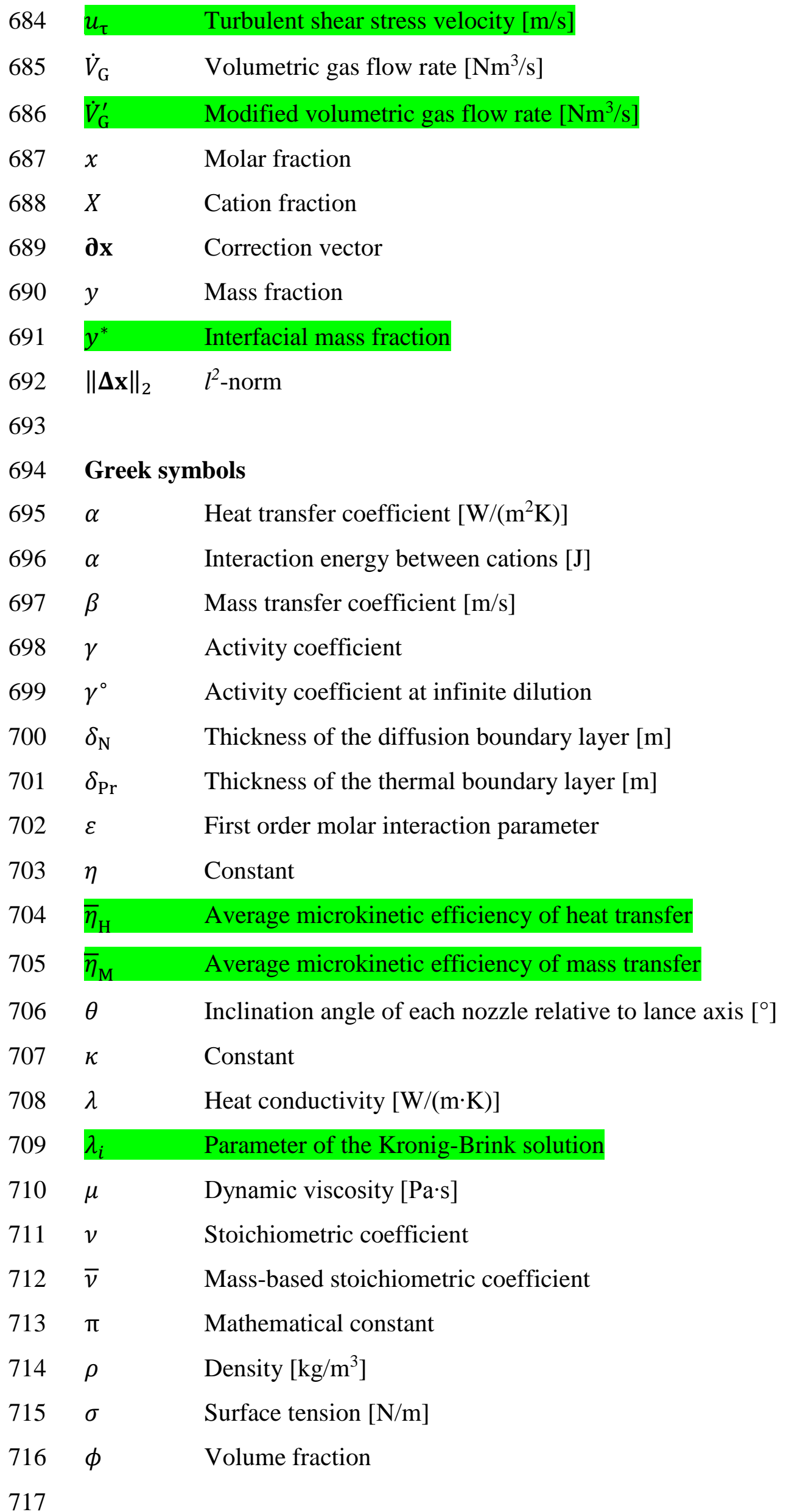




\section{Dimensionless numbers}

719 E Equilibrium number

$720 \quad \mathrm{Fo}_{\mathrm{H}} \quad$ Fourier number for heat transfer

$721 \quad \mathrm{Fo}_{\mathrm{M}} \quad$ Fourier number for mass transfer

$722 \quad \overline{\mathrm{Gr}} \quad$ Mean Grashof number

$723 \quad \mathrm{Gr}_{\mathrm{H}} \quad$ Grashof number for heat transfer

$724 \mathrm{Gr}_{\mathrm{M}} \quad$ Grashof number for mass transfer

$725 \mathrm{~N}_{\mathrm{B}} \quad$ Blowing number

$726 \quad \mathrm{~N}_{\mathrm{B}}^{\prime} \quad$ Modified blowing number

$727 \mathrm{Nu} \quad$ Nusselt number

728 Sc Schmidt number

729 Sh Sherwood number

730 Pr Prandtl number

$731 \quad \operatorname{Re} \quad$ Reynolds number

732

733 Subscripts and superscripts

734 cav Cavity

735 bath Steel bath

736 em Gas-metal-slag emulsion

$737 \quad$ G $\quad$ Gas phase

$738 \quad \mathrm{H} \quad$ Henrian standard state

739 in Gas flow into the system

740 jet Gas jet

741 L Liquid metal phase

742 md Metal droplet

743 out Gas flow out of the system

744 plume Gas plume

$745 \mathrm{R} \quad$ Raoultian standard state

746 rel Relative

747 S Slag phase

748 STP Standard temperature and pressure according to the DIN 1343 standard $^{[49]}$ :

$749273.15 \mathrm{~K}\left(0^{\circ} \mathrm{C}\right)$ and $101325 \mathrm{~Pa}$.

750 slag Top slag

751 (1) Liquid state 


$\begin{array}{lll}752 & (\mathrm{~s}) & \text { Solid state } \\ 753 & & \\ 754 & \text { Indices } & \\ 755 & i & \text { Size class } \\ 756 & i & \text { Species } \\ 757 & n & \text { Number of species } \\ 758 & r & \text { Number of reactions } \\ 759 & \psi & \text { Phase } \\ 760 & \omega & \text { Reaction interface }\end{array}$

\section{References}

[1] B. V. Patil, A. H. Chan and R. J. Choulet: Refining of Stainless Steels, pp. 715-741, In: R. J. Fruehan: The Making, Shaping and Treating of Steel. $11^{\text {th }}$ Edition Steel Making and Refining, The AISE Steel Foundation, Pittsburgh, PA, USA, 1998.

[2] J.-H. Wei, J.-C. Ma, Y.-Y. Fan, N.-W. Yu, S.-L. Yang, S.-H. Xiang and D.-P. Zhu: Ironmaking Steelmaking, 1999, vol. 26, pp. 363-371.

[3] P. Ternstedt, A. Tilliander, P. G. Jönsson and M. Iguchi: ISIJ Int., 2010, vol. 50, pp. 663-667.

[4] J.-H. Wei, H.-L. Zhu, H.-B. Chi and H.-J. Wang: ISIJ Int., 2010, vol. 50, pp. 26-34.

[5] J.-H. Wei, Y. He and G.-M. Shi: Steel Res. Int., 2011, vol. 82, pp. 693-702.

[6] H. Gorges, W. Pulvermacher, W. Rubens and H.-A. Dierstein: Stahl Eisen, 1979, vol. 99, pp. 1310-1312.

[7] P. R. Scheller and F.-J. Wahlers: ISIJ Int., 1996, vol. 36, pp. S69-S72.

[8] H.-L. Zhu, J.-H. Wei, G.-M. Shi, J.-H. Shu, Q.-Y. Jiang and H.-B. Chi: Steel Res. Int., 2007, vol. 78, pp. 305-310.

[9] T. Watanabe and T. Tohge: Tetsu-to-Hagané, 1973, vol. 59, pp. 1224-1236.

[10] S. Asai and J. Szekely: Metall. Trans., 1974, vol. 5, pp. 651-657.

[11] J. Szekely and S. Asai: Metall. Trans., 1974, vol. 5, pp. 1573-1580.

[12] R. J. Fruehan: Ironmaking Steelmaking, 1976, vol. 3, pp. 153-158.

[13] T. Ohno and T. Nishida: Tetsu-to-Hagané, 1977, vol. 63, pp. 2094-2099.

[14] T. Deb Roy and D. G. C. Robertson: Ironmaking Steelmaking, 1978, vol. 5, pp. 198-206. 
[15] T. Deb Roy, D. G. C. Robertson and J. C. C. Leach: Ironmaking Steelmaking, 1978, vol. 5, pp. 207-210.

[16] A. E. Semin, A. P. Pavlenko, T. Andzhum and E. A. Shuklina: Steel USSR, 1983, vol. 13, pp. 95-97.

[17] T. Tohge, Y. Fujita and T. Watanabe: Proceedings of the $4^{\text {th }}$ Process Technology Conference, Chicago, IL, USA, 1984, pp. 129-36.

[18] P. Sjöberg: Some aspects on the scrap based production of stainless steels, Doctoral thesis, Royal Institute of Technology, Stockholm, Sweden, 1994.

[19] J. Reichel and J. Szekely: Iron Steelmaker, 1995, vol. 22, pp. 41-48.

[20] M. Görnerup and P. Sjöberg: Ironmaking Steelmaking, 1999, vol. 26, pp. 58-63.

[21] J.-H. Wei and D.-P. Zhu: Metall. Mater. Trans. B, 2002, vol. 33, pp. 111-119.

[22] J.-H. Wei and D.-P. Zhu: Metall. Mater. Trans. B, 2002, vol. 33, pp. 121-127.

[23] N. Kikuchi, K. Yamaguchi, Y. Kishimoto, S. Takeuchi and H. Nishikawa: Tetsu-to-Hagané, 2002, vol. 88, pp. 32-39.

[24] B. Deo and V. Srivastava: Mater. Manuf. Process., 2003, vol. 18, pp. 401-108.

[25] B. Kleimt, R. Lichterbeck and C. Burkat: Stahl Eisen, 2007, vol. 127, pp. 35-41.

[26] G.-M. Shi, J.-H. Wei, H.-L. Zhu, J.-H. Shu, Q.-Y. Jiang and H.-B. Chi: Steel Res. Int., 2007, vol. 78, pp. 311-317.

[27] M. Järvinen, A. Kärnä and T. Fabritius: Steel Res. Int., 2009, vol. 80, pp. 429-436.

[28] J.-H. Wei, Y. Cao, H.-L. Zhu and H.-B. Chi: ISIJ Int., 2011, vol. 51, pp. 365-374.

[29] M. P. Järvinen, S. Pisilä, A. Kärnä, T. Ikäheimonen, P. Kupari and T. Fabritius: Steel Res. Int., 2011, vol. 82, pp. 638-649.

[30] S. E. Pisilä, M. P. Järvinen, A. Kärnä, T. Ikäheimonen, T. Fabritius and P. Kupari: Steel Res. Int., 2011, vol. 82, pp. 650-657.

[31] D. R. Swinbourne, T. S. Kho, B. Blanpain, S. Arnout and D. E. Langberg: Miner. Process. Extr. Metall., 2012, vol. 121, pp. 23-31.

[32] N. Å. I. Andersson, A. Tilliander, L. T. I. Jonsson and P. G. Jönsson: Steel Res. Int., 2012, vol. 83, pp. 1039-1052.

[33] N. Å. I. Andersson, A. Tilliander, L. T. I. Jonsson and P. G. Jönsson: Steel Res. Int., 2013, vol. 84, pp. 169-177.

[34] N. Å. I. Andersson, A. Tilliander, L. T. I. Jonsson and P. G. Jönsson: Ironmaking Steelmaking, 2013, vol. 40, pp. 390-397. 
813

[35] N. Å. I. Andersson, A. Tilliander, L. T. I. Jonsson and P. G. Jönsson: Ironmaking Steelmaking, 2013, vol. 40, pp. 551-558.

[36] V.-V. Visuri, M. Järvinen, P. Sulasalmi, E.-P. Heikkinen, J. Savolainen and T. Fabritius: ISIJ Int., 2013, vol. 53, pp. 603-612.

[37] V.-V. Visuri, M. Järvinen, J. Savolainen, P. Sulasalmi, E.-P. Heikkinen and T. Fabritius: ISIJ Int., 2013, vol. 53, pp. 613-621.

[38] R. J. Fruehan: Metall. Trans. B, 1975, vol. 6, pp. 573-578.

[39] Y. Tang, T. Fabritius and J. Härkki: Steel Res. Int., 2004, vol. 75, pp. 373-381.

[40] J. Riipi, T. Fabritius, E.-P. Heikkinen, P. Kupari and A. Kärnä: ISIJ Int., 2009, vol. 49, pp. 14681473.

[41] R. Ding, B. Blanpain, P. T. Jones and P. Wollants: Metall. Mater. Trans. B, 2000, vol. 31, pp. 197-206.

[42] Y. Uchida, N. Kikuchi, K. Yamaguchi, Y. Kishimoto, S. Takeuchi and H. Nishikawa: Proceedings of the $2^{\text {nd }}$ International Conference on Process Development in Iron and Steelmaking, Luleå, Sweden, 2004, pp. 69-78.

[43] J.-H. Wei and Y. Li: Steel Res. Int., 2015, vol. 86, pp. 189-211.

[44] V.-V. Visuri, M. Järvinen, A. Kärnä, E.-P. Heikkinen, P. Kupari and T. Fabritius: $A$ Mathematical Model for Reactions during Top-Blowing in the AOD Process: Validation and Results, Process Metallurgy Research Unit, University of Oulu, unpublished research, 2016.

[45] M. Järvinen, V.-V. Visuri, S. Pisilä, A. Kärnä, P. Sulasalmi, E.-P. Heikkinen and T. Fabritius: Mater. Sci. Forum, 2013, vol. 762, pp. 236-241.

[46] M. Järvinen, V.-V. Visuri, E.-P. Heikkinen, A. Kärnä, P. Sulasalmi, C. De Blasio and T. Fabritius: ISIJ Int., 2016, vol. 56, pp. 1543-1552.

[47] Z. Song: Modeling of Gas flows in Steelmaking Decarburization Processes, p. 60, Doctoral thesis, Royal Institute of Technology, Stockholm, Sweden, 2013.

[48] Y. Tang, T. Fabritius and J. Härkki: Appl. Math. Model., 2005, vol. 29, pp. 497-514.

[49] Deutsches Institut für Normung e.V.: DIN 1343, Referenzzustand, Normzustand, Normvolumen; Begriffe und Werte, DIN1343, Referenzzustand, Normzustand, Normvolumen; Begriffe und Werte, 1990.

[50] R. Taylor and R. Krishna: Multicomponent Mass Transfer, p. 126, John Wiley \& Sons, Inc., New York, NY, USA, 1993.

[51] R. I. L. Guthrie: Engineering in Process Metallurgy, p. 282, Clarendon Press, Oxford, United Kingdom, 1989.

[52] B. Deo and R. Boom: Fundamentals of Steelmaking Metallurgy, p. 170/176, Prentice Hall International, Hertfordshire, United Kingdom, 1993. 
848

849

850

851

852

853

854

855

856

857

858

859

860

861

862

863

864

865

866

867

868

869

870

871

872

873

874

875

876

877

[53] H.-J. Odenthal, U. Falkenreck and J. Schlüter: Proceedings of the European Conference on Computational Fluid Dynamics, Egmond aan Zee, The Netherlands, 2006, pp. 21.

[54] N. Molloy: J. Iron Steel Inst., 1970, vol. 208, pp. 943-950.

[55] S. Sabah and G. Brooks: ISIJ Int., 2014, vol. 54, pp. 836-844.

[56] X. Zhou, M. Ersson, L. Zhong, J. Yu and P. Jönsson: Steel Res. Int., 2014, vol. 85, pp. 273-281.

[57] S. K. Sharma, J. W. Hlinka and D. W. Kern: Iron Steelmaker, 1977, vol. 24, pp. 7-18.

[58] D. Nakazono, K.-I. Abe, M. Nishida and K. Kurita: ISIJ Int., 2004, vol. 44, pp. 91-99.

[59] F. R. Cheslak, J. A. Nicholls and M. Sichel: J. Fluid Mech., 1969, vol. 36, pp. 55-63.

[60] S. N. Krivoshapko and V. N. Ivanov: Encyclopedia of Analytical Surfaces, p. 110, Springer International Publishing, Cham, Switzerland, 2015.

[61] C. K. Lee, J. H. Neilson and A. Gilchrist: Iron Steel Int., 1977, vol. 50, pp. 175-184.

[62] C. K. Lee, J. H. Neilson and A. Gilchrist: Ironmaking Steelmaking, 1977, vol. 4, pp. 329-337.

[63] S. C. Koria and K. W. Lange: Steel Res., 1987, vol. 58, pp. 421-426.

[64] K. W. Lange and S. C. Koria: Wechselwirkung zwischen Sauerstoffstrahl und Roheisenschmelze beim Sauerstoffaufblasverfahren, , Publ. Wiss. Film. Techn. Wiss./Naturw., Ser. 8, Nr. 9, Institut für den Wissenschaftlichen Film, Göttingen, Germany, 1983, Film D 1386.

[65] J.-H. Wei and L. Zeng: Steel Res. Int., 2012, vol. 83, pp. 1053-1070.

[66] S. C. Koria: Wechselwirkung zwischen einem Gasstrahl und flüssiger Metallschmelze, p. 14, Doctoral thesis, RWTH Aachen University, Aachen, Germany, 1981.

[67] Subagyo, G. A. Brooks, K. S. Coley and G. A. Irons: ISIJ Int., 2003, vol. 43, pp. 983-989.

[68] E. Schürmann and K. Rosenbach: Arch. Eisenhüttenwes., 1973, vol. 44, pp. 761-768.

[69] W. Rubens: Untersuchung der Schlackenwege und des Verschleißes des feuerfesten Ausmauerung bei modifizierten AOD-Verfahren zur Erzeugung rostfreier Stähle, p. 45, Doctoral thesis, Clausthal University of Technology, Clausthal-Zellerfeld, Germany, 1988.

[70] K. Koch, W. Münchberg, H. Zörcher and W. Rubens: Stahl Eisen, 1992, vol. 112, pp. 91-99.

[71] T. X. Zhu, K. S. Coley and G. A. Irons: Metall. Mater. Trans. B, 2012, vol. 43, pp. 751-757.

[72] E. T. Turkdogan: Chem. Eng. Sci., 1966, vol. 21, pp. 1133-1144.

[73] N. Standish and Q. L. He: ISIJ Int., 1989, vol. 29, pp. 455-461.

[74] I. Hahn: Untersuchungen zum Verspritzen von Schmelze in sekundärmetallurgischen Anlagen, p. 1, Doctoral thesis, RWTH Aachen University, Aachen, Germany, 1999. 
878 879

880

881

882

883

884

885

886

887

888

889

890

891

892

893

894 895

896

897

898

899

900

901

902

903

904

905

906

907

908

[75] A. Feiterna, D. Huin, F. Oeters, P.-V. Riboud and J.-L. Roth: Steel Res., 2000, vol. 71, pp. 6169.

[76] Z. Han and L. Holappa: ISIJ Int., 2003, vol. 43, pp. 292-297.

[77] Z. Han and L. Holappa: ISIJ Int., 2003, vol. 43, pp. 1698-1704.

[78] S. C. Koria and K. W. Lange: Ironmaking Steelmaking, 1983, vol. 10, pp. 160-168.

[79] K.-Y. Lee, H.-G. Lee and P. C. Hayes: ISIJ Int., 1998, vol. 38, pp. 1242-1247.

[80] H. W. Meyer, W. F. Porter, G. C. Smith and J. Szekely: J. Met., 1968, vol. 20, pp. 35-42.

[81] G. Lindstrand, P. G. Jönsson and A. Tilliander: Proceedings of the ISIJ-VDEh-Jernkontoret Joint Symposium, Osaka, Japan, 2013, pp. 106-13.

[82] A. Nordquist, A. Tilliander, K. Grönlund, G. Runnsjö and P. Jönsson: Ironmaking Steelmaking, 2009, vol. 36, pp. 421-431.

[83] W. Kleppe and F. Oeters: Arch. Eisenhüttenwes., 1977, vol. 48, pp. 139-143.

[84] S. Sabah, M. Alam, G. Brooks and J. Naser: 4th International Conference on Process Development in Iron and Steelmaking, Luleå, Sweden, 2012, pp. 125-34.

[85] S. Sabah and G. Brooks: Metall. Mater. Trans. B, 2015, vol. 46, pp. 863-872.

[86] M. Alam, G. Irons, G. Brooks, A. Fontana and J. Naser: ISIJ Int., 2011, vol. 51, pp. 1439-1447.

[87] S. Sarkar, P. Gupta, S. Basu and N. B. Ballal: Metall. Mater. Trans. B, 2015, vol. 46, pp. 961976.

[88] B. K. Rout, G. Brooks, Subagyo, M. A. Rhamdhani and Z. Li: Metall. Mater. Trans. B, 2016, vol. 47, pp. 3350-3361.

[89] S. C. Koria and K. W. Lange: Metall. Trans. B, 1984, vol. 15, pp. 109-116.

[90] C. Cicutti, M. Valdez, T. Pérez, J. Petroni, A. Gómez, R. Donayo and L. Ferro: Proceedings of the $6^{\text {th }}$ International Conference on Motel Slags, Fluxes and Salts, Stockholm, Sweden - Helsinki, Finland, 2000, pp. 1-17.

[91] S. C. Koria and K. W. Lange: Ironmaking Steelmaking, 1986, vol. 13, pp. 236-240.

[92] S.-Y. Kitamura and K. Okohira: Tetsu-to-Hagané, 1990, vol. 76, pp. 199-206.

[93] B. Deo, A. Karamcheti, A. Paul, P. Singh and R. P. Chhabra: ISIJ Int., 1996, vol. 36, pp. 658666.

[94] Q. L. He and N. Standish: ISIJ Int., 1990, vol. 30, pp. 356-361.

[95] G. Brooks, Y. Pan, Subagyo and K. Coley: Metall. Mater. Trans. B, 2005, vol. 36, pp. 525-535.

[96] R. C. Urquhart and W. G. Davenport: Can. Metall. Q., 1973, vol. 12, pp. 507-516. 
[97] Subagyo and G. A. Brooks: ISIJ Int., 2002, vol. 42, pp. 1182-1184.

910 [98] H. Gou, G. A. Irons and W.-K. Lu: Metall. Mater. Trans. B, 1996, vol. 27, pp. 195-201.

911 [99] F. Oeters: Metallurgie der Stahlherstellung, p. 162/174/337, Verlag Stahleisen mbH, Düsseldorf, 912 Germany, 1989.

913 [100] H. Lohe: Fortschr. -Ber. VDI-Z., 1967, Reihe 3, Nr. 15, pp. 1-59.

914 [101] N. Dogan, G. A. Brooks and M. A. Rhamdhani: ISIJ Int., 2011, vol. 51, pp. 1102-1109.

915 [102] F. Memoli, C. Mapelli, P. Ravanelli and M. Corbella: ISIJ Int., 2004, vol. 44, pp. 1342-1349.

916 [103] R. L. Steinberger and R. E. Treybal: AIChE Journal, 1960, vol. 6, pp. 227-232.

917 [104] K. W. Lange: Arch. Eisenhüttenwes., 1971, vol. 42, pp. 233-241.

918 [105] R. Kronig and J. C. Brink: Appl. Sci. Res., 1951, vol. 2, pp. 142-154.

919 [106] D. Colombet, D. Legendre, A. Cockx and P. Guiraud: Int. J. Heat Mass Tran., 2013, vol. 67, $920 \quad$ pp. 1096-1105.

921 [107] P. M. Heertjes, W. A. Holve and H. Talsma: Chem. Eng. Sci., 1954, vol. 3, pp. 122-142.

[108] R. Clift, J. R. Grace and M. E. Weber: Bubbles, drops and particles, Academic Press, New York, USA, 1978.

924 [109] P. H. Calderbank: Chem. Engr., 1967, vol. 45, pp. 209-233.

925 [110] G. K. Sigworth and J. F. Elliott: Met. Sci., 1974, vol. 8, pp. 298-310.

926 [111] Outotec Oyj: HSC Chemistry 8, 2015.

927 [112] A. D. Pelton and C. W. Bale: Metall. Trans. A, 1986, vol. 17, pp. 1211-1215.

928 [113] A. V. Alpatov and S. N. Paderin: Russ. Metall., 2010, vol. 2010, pp. 557-564.

929 [114] W. E. Slye and R. J. Fruehan: Proceedings of the $57^{\text {th }}$ Electric Furnace Conference, Pittsburgh, $930 \quad$ PA, USA, 1999, pp. 401-12.

931 [115] S. Ueno, Y. Waseda, T. Jacob K. and S. Tamaki: Steel Res., 1988, vol. 59, pp. 474-483.

932 [116] K. V. Malyutin and S. N. Paderin: Russ. Metall., 2007, vol. 2007, pp. 545-551.

933 [117] J. Szekely and N. J. Themelis: Rate Phenomena in Process Metallurgy, p. 459, John Wiley \&

[118] K. Nagata, Y. Ono, T. Ejima and T. Yamamura: Diffusion, pp. 181-204, In: Y. Kawai and Y. Shiraishi: Handbook of Physico-chemical Properties at High Temperatures, The Iron and Steel Institute of Japan, Tokyo, Japan, 1988. 
938

[119] IAEA: Thermophysical Properties of Materials for Nuclear Engineering: A Tutorial and Collection of Data, p. 169, International Atomic Energy Agency, Vienna, Austria, 2008.

[120] B. J. Keene and K. C. Mills: Densities of molten slags, pp. 313-348, In: Verein Deutscher Eisenhüttenleute: Slag Atlas $2^{\text {nd }}$ Edition, Verlag Stahleisen GmbH, Düsseldorf, Germany, 1995.

[121] C. R. Wilke: J. Chem. Phys., 1950, vol. 18, pp. 517-519.

[122] R. B. Bird, W. E. Stewart and E. N. Lightfoot: Transport Phenomena, p. 23, John Wiley \& Sons, Inc., Singapore, 1960.

[123] G. H. Geiger and D. R. Poirier: Transport phenomena in metallurgy, p. 11, Addison-Wesley Publishing Company, Reading, MA, USA, 1973.

[124] L. D. Cloutman: A Database of Selected Transport Coefficients for Combustion Studies, p. 5, Lawrence Livermore National Laboratory, Livermore, CA, USA, 1993.

[125] L. Forsbacka, L. Holappa, A. Kondratiev and E. Jak: Steel Res. Int., 2007, vol. 78, pp. 676-684.

[126] D. G. Thomas: J. Colloid Sci., 1965, vol. 20, pp. 267-277.

[127] C. R. Wilke and C. Y. Lee: Ind. Eng. Chem., 1955, vol. 47, pp. 1253-1257.

[128] K. C. Mills: Diffusion coefficients in molten slags, pp. 541-556, In: Verein Deutscher Eisenhüttenleute: Slag Atlas $2^{\text {nd }}$ Edition, Verlag Stahleisen GmbH, Düsseldorf, Germany, 1995.

[129] C. F. Wuppermann: Mathematische Modellierung der fluidinduzierten Behälterschwingung beim AOD-Prozess, p. 58, Doctoral thesis, RWTH Aachen University, Aachen, Germany, 2013.

[130] Outotec Research Oy: HSC Chemistry 7, 1974-2009.

[131] O. Wijk: Stainless Steelmaking in Converters, pp. 280-301, In: T. A. Engh: Principles of Metal Refining, Oxford University Press, Oxford, United Kingdom, 1992.

[132] G. Urbain: Steel Res., 1987, vol. 58, pp. 111-116.

[133] A. Einstein: Ann. Phys., 1906, vol. 19, pp. 289-306.

[134] E. Guth and R. Simha: Kolloid Z., 1936, vol. 74, pp. 266-275.

[135] E. Guth: J. Appl. Phys., 1945, vol. 16, pp. 20-25.

[136] H. M. Smallwood: J. Appl. Phys., 1944, vol. 15, pp. 758-766.

[137] H. C. Brinkman: J. Chem. Phys., 1952, vol. 20, pp. 571.

[138] J. Happel: J. Appl. Phys., 1957, vol. 28, pp. 1288-1292.

[139] T. Kitano, T. Kataoka and T. Shirota: Rheol. Acta, 1981, vol. 20, pp. 207-209.

[140] E. Kreyszig, H. Kreyszig and E. J. Norminton: Advanced Engineering Mathematics Tenth Edition, p. 909, John Wiley \& Sons, Inc., Hoboken, NJ, USA, 2011. 


\section{$970 \quad$ List of tables}

971 Table 1. Equations for calculating the geometry of the cavity. ${ }^{[63]}$

972 Table 2. Employed first-order molar interaction parameters in liquid iron at $1873 \mathrm{~K}\left(1600^{\circ} \mathrm{C}\right)$.

973 Table 3. Interaction coefficients of the slag model. ${ }^{[21]}$

974 Table 4. Employed models and parameters for physical properties. 


\section{List of figures}

976 Figure 1. Schematic illustration of combined-blowing in an AOD vessel.

977 Figure 2. Schematic illustration of the interaction of the reaction interfaces.

978 Figure 3. Schematic illustration of the gas jet impact area with a one-hole lance.

979 Figure 4. Schematic illustration of the gas jet impact area with a 3-hole lance with non-coalescing 980 (A) and coalescing (B) cavities.

981 Figure 5. Calculated relative viscosity as a function of the volume fraction of solids ${ }^{[126,133-139]}$. 982 Figure 6. Flowchart of the reaction model.

983 